\title{
Phosphatidylinositol synthesis at the endoplasmic reticulum
}

Nicholas J. Blunsom and Shamshad Cockcroft

Dept. of Neuroscience, Physiology and Pharmacology, Division of Biosciences, University College London, London WC1E 6JJ, UK;

Address correspondence to: Shamshad Cockcroft, University College London UK; Phone: 0044-20-7679-6259; Email: s.cockcroft@ucl.ac.uk

\section{Highlights}

- The enzymes CDP-diacylglycerol synthase (CDS) and phosphatidylinositol synthase, required for de novo synthesis of phosphatidylinositol (PI), are localised at the endoplasmic reticulum;

- The acyl chains of the newly-synthesised phosphatidylinositol is remodelled by phospholipases A and acyltransferases at the ER;

- The remodelled phosphatidylinositol is highly enriched in stearic acid at the $s n-1$ position and arachidonic acid at the $s n-2$ position in normal mammalian tissue;

- In cancer cells, mutated p53 results in changes to the phosphatidylinositol acyl chain composition to shorter chain length;

- Phosphatidylinositol resynthesis, stimulated during phospholipase $\mathrm{C}$ signalling, is regulated through changes in CDS1 expression via protein kinase $\mathrm{C}$ and $\mathrm{cFos}$;

Keywords: CDP-diacylglycerol synthase; Phosphatidylinositol synthase; p53; cFos; phosphatidylinositol synthesis; protein kinase C; Remodelling of phosphatidylinositol;

Abbreviations: ER, endoplasmic reticulum; PM, plasma membrane; PC, phosphatidylcholine; PI, phosphatidylinositol; PS, phosphatidylserine; PE, phosphatidylethanolamine; TG, triacylglycerol; PA, phosphatidic acid; LPA, lysoPA; DG, diacylglycerol; CDP-DG, CDPdiacylglycerol; PKC, protein kinase C; DGK, diacylglycerol kinase; LPIAT1, lysophosphatidylinositol acyltransferase 1; PLC, phospholipase C; $\mathrm{PI}(4,5) \mathrm{P}_{2}$, phosphatidylinositol $(4,5)$ bisphosphate; $\mathrm{IP}_{3}$, inositol $(1,4,5)$ triphosphate; PLD, phospholipase D; G-3-P, glycerol3-phosphate; GPAT, glycerol phosphate acyl transferase; LPAAT, lysoPA acyl transferase; PAP, PA phosphatase (also known as lipin); PIS, phosphatidylinositol synthase; PIP synthase, phosphatidylinositol phosphate synthase; CNEP-1, C-terminal domain nuclear envelope phosphatase 1; 


\section{Abstract}

Phosphatidylinositol (PI) is a minor phospholipid with a characteristic fatty acid profile; it is highly enriched in stearic acid at the $s n-1$ position and arachidonic acid at the $s n-2$ position. PI is phosphorylated into seven specific derivatives, and individual species are involved in a vast array of cellular functions including signalling, membrane traffic, ion channel regulation and actin dynamics. De novo PI synthesis takes place at the endoplasmic reticulum where phosphatidic acid (PA) is converted to PI in two enzymatic steps. PA is also produced at the plasma membrane during phospholipase $\mathrm{C}$ signalling, where hydrolysis of phosphatidylinositol $(4,5)$ bisphosphate $\left(\mathrm{PI}(4,5) \mathrm{P}_{2}\right)$ leads to the production of diacylglycerol which is rapidly phosphorylated to PA. This PA is transferred to the ER to be also recycled back to PI. For the synthesis of PI, CDP-diacylglycerol synthase (CDS) converts PA to the intermediate, CDPDG, which is then used by PI synthase to make PI. The de novo synthesised PI undergoes remodelling to acquire its characteristic fatty acid profile, which is altered in p53-mutated cancer cells. In mammals, there are two CDS enzymes at the ER, CDS1 and CDS2. In this review, we summarise the de novo synthesis of PI at the ER and the enzymes involved in its subsequent remodelling to acquire its characteristic acyl chains. We discuss how CDS, the rate limiting enzymes in PI synthesis are regulated by different mechanisms. During phospholipase C signalling, the CDS1 enzyme is specifically upregulated by cFos via protein kinase C. 


\section{Introduction}

Phosphatidylinositol (PI) is a minor anionic lipid in mammalian cells. It is composed of a glycerol backbone, two acyl chains esterified at the $s n-1$ and $s n-2$ positions and an inositol ring linked to the $s n-3$ position by a phosphate (Fig. 1). Although PI constitutes only 5-10\% of total cellular lipids in mammalian cells, it plays a major role primarily as it is the source for generating seven phosphorylated derivatives of PI. The inositol headgroup has three hydroxyls that are accessible for phosphorylation by lipid kinases and can be mono-, di- or triphosphorylated, increasing its negative charge with multiple phosphorylations (Fig. 1). Phosphorylated PIs have many functions in the cell including membrane traffic, recruitment of proteins, regulation of the actin cytoskeleton, endocytosis, autophagy, and cell signalling via phospholipase C (PLC) and phosphoinositide 3-kinases [1-6].

The synthesis of PI is confined to the endoplasmic reticulum (ER), the largest membrane compartment of the cell, which is also the site of synthesis of the major phospholipids, phosphatidylcholine (PC), phosphatidylethanolamine (PE) and phosphatidylserine (PS) and triacylglycerol (TG). Phosphorylation of PI mainly takes place on the cytosolic facing surface of other organelles by resident kinases but not at the ER. For example, at the plasma membrane, PI is converted to $\mathrm{PI}(4,5) \mathrm{P}_{2}$ by sequential phosphorylation by the Type III $\alpha$ PI 4-kinase and PIP 5-kinase where it is a substrate for both phosphoinositide 3-kinases and PLCs during signal transduction. Phospholipase $\mathrm{C}$ is the only enzyme that degrades $\mathrm{PI}(4,5) \mathrm{P}_{2}$ such that it requires the resynthesis of the PI backbone. There are thirteen PLCs in the mammalian genome, which are differentially regulated [7-9]. Phospholipase Cs are present in almost all cells and their activity can be regulated by agonists/hormones/neurotransmitters acting on cell surface receptors including G-protein-coupled receptors as well as receptor tyrosine kinases. 
Additionally, some PLCs are activated by increases in cytosol $\mathrm{Ca}^{2+}$ and by small GTPases including Rac [7, 9]. Phospholipase $\mathrm{C}$ hydrolyses $\mathrm{PI}(4,5) \mathrm{P}_{2}$ and this results not only in the formation of the two second messengers, diacylglycerol (DG) and inositol $(1,4,5)$ trisphosphate $\left(\mathrm{IP}_{3}\right)$, but it simultaneously also causes a decrease in $\mathrm{PI}(4,5) \mathrm{P}_{2}$ levels. As $\mathrm{PI}(4,5) \mathrm{P}_{2}$ regulates ion channel function as well as required for the endocytic process at the plasma membrane, resynthesis of $\mathrm{PI}(4,5) \mathrm{P}_{2}$ and thus resynthesis of $\mathrm{PI}$ at the ER has to be tightly coupled to PLC signalling at the plasma membrane (Fig. 2).

The intersection point between the de novo synthesis of PI at the ER and PI resynthesis subsequent to PLC signalling at the PM is the intermediate, phosphatidic acid (PA). At the plasma membrane, PA is an indirect product of PLC and a direct product of phospholipase D (PLD) whilst at the ER it is formed from the precursor, glycerol-3-phosphate (G-3-P) (Fig. 3). For de novo synthesis, G-3-P undergoes two rounds of acylation through the actions of acyltransferases. The first acylation forms lysophosphatidic acid (LPA) whereas the second acylation produces PA. One of the unusual features of PI in mammalian cells is its characteristic fatty acid composition. PI is highly enriched in stearic acid (C18:0) at the $s n-1$ position and with arachidonic acid (C20:4) at the $s n-2$ position (designated C18:0/C20:4 (the number of carbons : number of double bonds in each fatty acid) or 38:4 for the whole molecule.)) Depending on the specific tissue and cell type, up to 40-85\% of all PI species possess this acyl chain composition (C38:4) with the second most prevalent species of PI being C38:3 [10-12].

In this review, we summarise and discuss the enzymes involved in de novo synthesis of PI, remodelling of PI to acquire its characteristic fatty acid composition and resynthesis of PI after PLC signalling. The changes in the characteristic fatty acid profile of PI in cancer cells will be 
highlighted. As the ER is a continuous membrane system comprising of the nuclear envelope, flat sheets, and a network of highly-curved tubules, the localisation of the PI synthesis machinery within the different ER compartments will be discussed. Finally, we will describe studies that identify mechanisms that can regulate the synthesis of PI via changes in expression of the CDP-DG synthase (CDS) enzymes.

\section{Enzymes involved in PI synthesis}

\subsection{PA synthesis by acyl transferases (GPATS and LPAATS)}

During the de novo biosynthesis of all phospholipids and neutral lipids, fatty acids are successively introduced into the $s n-1$ and $s n-2$ positions to the substrate G-3-P to make PA (Fig. 2). PA can have two fates; it is either dephosphorylated to DG for the synthesis of phosphatidylcholine (PC) and phosphatidylethanolamine (PE) or triacylglycerols (TG) or converted to CDP-DG for the synthesis of PI. The de novo biosynthesis of PA at the ER starts with the acylation of G-3-P to make lysoPA (LPA) by G-3-P acyltransferase (GPAT). Four mammalian GPATs have been cloned with the closely-related GPAT3 and GPAT4 localised to the ER whilst the closely-related GPAT1 and GPAT2 localised at the outer mitochondrial membrane $[13,14]$. LPA is further acylated by the enzyme, lysophosphatidic acid acyltransferase (LPAAT) which esterifies a fatty acyl-CoA at the $s n-2$ position of the glycerol backbone. Of the five canonical LPAATs, at least, three LPAATs $(1,2,3)$ are localised at the ER whilst two LPAATs (4 and 5) are localised at the ER and mitochondria [15, 16]. Interestingly, loss of LPAAT4 causes a decrease in PI, PC and PE levels in the brain with impaired spatial learning and memory $[15,17]$. LPAATS appear to generate distinct pools of PA that enter dedicated biosynthetic pathways as loss of individual LPAATs lead to unique phenotypes (reviewed in [15]). Analysis of the acyl chain composition of PA from mouse liver 
and brain shows $\mathrm{C} 34: 1(\mathrm{C} 16: 0 / \mathrm{C} 18: 1)$ as the major species with some contributions from $\mathrm{C} 36: 1$ and C38:4 $[12,18]$. Since PA can be routed to make the major phospholipids, neutral lipids as well as PI (Fig. 3), the selectivity of a particular species of PA by CDS enzymes could be a contributory factor in determining the fatty acyl composition of the de novo-synthesised PI (see below).

\subsection{CDP-DG synthetases (CDS)}

The next step in the synthesis of PI is the conversion of PA to the intermediate CDP-DG (Fig. 2). This is the rate-limiting step in the synthesis of PI [19]. PA can be converted to DG or to CDP-DG at the ER and this partitioning is directed by the action of CDS enzymes and PA phosphatases (PAPs also known as lipins) (Fig. 3). How this branchpoint is regulated is not fully understood. In mice, humans and zebrafish, two homologous genes of CDS (CDS1 and CDS2) have been identified that are 73\% identical and 92\% similar at the amino acid level [2025]. Human CDS1 and CDS2 are of similar size; CDS1 is 461 amino acids long with a calculated molecular weight of $\sim 53 \mathrm{kDa}$ whilst CDS2 is 445 amino acids with a calculated molecular weight of $\sim 51 \mathrm{kDa}$ (Fig. 4). A single CDS gene homologous to mammalian CDS is found in most species including E coli [26], S. cerevisiae [27] and Drosophila [28]. The structure of Cds from the bacterium, Thermotoga maritama (TmCdsA) identifies a homodimer with each monomer containing nine transmembrane helices arranged into a novel fold with three domains (Fig. 4A, B). The enzyme can simultaneously accept CTP and PA in an unusual funnel-shaped cavity which penetrates half way into the membrane [29]. CDS1 and CDS2 are also found as a dimer when expressed in COS-7 cells [30]. 
CDS activity is also present in mitochondria, where it is required for cardiolipin synthesis [31]. This CDS activity is encoded by Tam41, originally identified in yeast, [32]; Tam41 protein is found in the matrix of the mitochondria as a peripheral protein and bears no sequence relationship to CDS1 and CDS2 (Fig. 4A-C). Likewise, mammalian cells also contain TAMM41 in mitochondria, a peripheral protein required for cardiolipin synthesis [30]. TAMM41 contains the MMP37 domain (MMP37, mitochondrial matrix proteins of $37 \mathrm{kDa}$ ) (Fig. 4).

A limited number of studies have addressed whether CDS1 and CDS2 have a preference for the acyl chain composition of their substrate, PA. Purified rat CDS1 from brain was found to select $s n$-1-stearoyl-sn-2-arachidonoyl-PA as its substrate. However, substantial CDS activity was also observed using egg yolk PA as well as with di C18:1 PA but very little with di C18:0 PA. (Egg yolk PA mainly comprises of saturated (C16:0 (34\%) and C18:0 (11\%)) and monounsaturated fatty acids (18:1 (31\%)) and some di-unsaturated fatty acids (18:2 (18\%))) [22]. When membranes prepared from COS-7 cells expressing CDS1 or CDS2 enzymes were examined using different PA species, CDS1 was able to use PA with many different fatty acid compositions, whilst CDS2 preferentially used PA which contains stearic and arachidonic acid at the $s n-1$ and $s n-2$ position respectively [33]. As described in Section 3, PI can also acquire its characteristic acyl composition after de novo synthesis by remodelling the acyl chains using phospholipases and acyltransferases.

CDS activity in the ER is essential for PI synthesis. Two separate studies, conducted in H9c2 cardiomyoblasts and in HeLa cells, have reported that knockdown of either CDS1 or CDS2 using siRNA results in a decrease in PI levels [34, 35]. Knockdown of either CDS1 or CDS2 
in H9c2 cardiomyoblasts results in loss of stress fibres, disruption of Golgi and fragmentation of mitochondria likely resulting from the loss of polyphosphoinositides [34]. In HeLa cells, PA levels are increased upon CDS1 or CDS2 knockdown [35]. Interestingly, many more PA species are significantly increased upon CDS1 knockdown compared to CDS2 knockdown. In the presence of oleic acid, CDS1 or CD2 knockdown Hela cells exhibit the formation of supersized lipid droplets (LDs) due to an increase in triacylglycerol (TG). This is a consequence of PA accumulation in the knockdown cells; the PA, which usually would have been used for PI synthesis, is re-routed and used for TG production (Fig. 3). Studies done in other organisms including different yeasts (e.g. S. Cerevisiae and S. Pombe) and Drosophila report that loss of the single CDS gene results in changes in lipid composition. In these organisms, $C d s$ mutants generally show a decrease in PI together with an increase in PA with the PA shunted towards triacylglycerol [36-39].

\subsection{Phosphatidylinositol Synthase (PIS)}

CDP-DG is the substrate for the enzyme PI synthase (PIS) (also referred to as CDPdiacylglycerol-inositol 3-phosphatidyltransferase (CDIPT). PIS can catalyse the reversible exchange of inositol for CMP on CDP-DG resulting in the production of PI [40]. However, it is unlikely that the enzyme will work in the reverse direction in cells due to low levels of CMP under normal conditions. Most eukaryotes (with the exception of plants [41]) express a single PIS enzyme, which localizes to the ER. PIS is a transmembrane enzyme, which is related to the prokaryotic enzyme, PIP synthase, where CDP-DG together with inositol-3phosphate is synthesised into PIP [42]. (PIS is classified as a CDP-alcohol phosphotransferase, which use CDP-DG as donor substrate for this reaction, and either inositol in eukaryotes or inositol phosphate in prokaryotes as the acceptor alcohol). Whilst the structure of eukaryotic 
PIS is not available, the structure of PIP synthase from Renibacterium salmoninarum, with and without bound CDP-DG has been determined [42]. These structures reveal the location of the acceptor site, and the molecular determinants of substrate specificity and catalysis. This structure offers a view of the transmembrane (TM) architecture and catalytic machinery of this enzyme family. RsPIP synthase adopts a homodimeric architecture, with each protomer possessing six transmembrane helices surrounding a large polar cavity. PIS is expected to have a similar architecture to RsPIP synthase [42]. The acyl chain specificity of the substrate for PIS, CDP-DG, has been examined and PIS appears to exhibit no acyl chain specificity toward its substrates when analysed in vitro in a mixed micelle assay which could bias the data [43].

\section{Remodelling of PI to acquire its characteristic fatty acid chains}

One of the most striking characteristics of mammalian PI is its fatty acyl chain composition. The PI fingerprint is predominantly 38:4 carbon acyl chain content (C18:0/C20:4) in many primary rodent tissues including liver, kidney, brain, macrophages and platelets $[10-12,44-$ 46]. This enrichment of $s n$-1-stearoyl-sn-2-arachidonoyl species is variable dependent on the tissue. In brain, this enrichment is greater than $85 \%$ of the total PI content whilst in both human and mouse platelets, it is $38 \%$, with the remainder being C38:3 (19\%) and the saturated C32:0 (20\%) representing $>75 \%$ of PI. During thrombin stimulation, when PLC is activated, a decrease in PI occurs and the main decrease observed is in the unsaturated species [10]. This would suggest that some kind of selection takes place when PI is converted into $\mathrm{PI}(4,5) \mathrm{P}_{2}$ by the lipid kinases, the substrate for PLC. Saturated PI is not a good substrate for the lipid kinases or alternatively, it is localised at the ER where lipid kinases are not present. 
How does PI acquire its specific fatty acid composition? Although CDS enzymes may select PA enriched in stearic and arachidonic acid, fatty acid remodelling after the de novo synthesis of PI through sequential de-acylation and re-acylation reactions is also very important $[47,48]$. De novo synthesised PI is enriched in saturated and mono-unsaturated acyl chains $[19,47,48]$ and is remodelled such that majority of the PI molecules acquire stearic acid at the $s n-1$ position and arachidonic acid at the $s n-2$ position. This remodelling of PI occurs by the concerted efforts of phospholipases A to cleave the fatty acid followed by acylation by acyl-CoA-specific lysophospholipid acyltransferase enzymes that incorporate a new fatty acid (Fig. 5).

\subsection{Phosphatidylinositol-specific Phospholipases $A_{1}$ and $A_{2}$}

LysoPIs can exist as $s n-1$ acylated or $s n-2$ acylated and are produced by distinct phospholipases. For remodelling the $s n-2$ position, $s n-1$ acylated lyso-PI has to be generated by the activity of PLA $\mathrm{P}_{2}$. There is an abundance of PLA $\mathrm{P}_{2}$ enzymes but one specifically involved in PI remodelling has yet to be identified [49]. For PI to acquire stearic acid at the $s n-1$ position, a phospholipase $A_{1}$ specific for PI to make 2-acylated lysoPI is required (Fig. 5). One such candidate enzyme is a member of the DDHD-domain containing family of intracellular phospholipases $\mathrm{A}_{1}$ [50]. The DDHD domain is 180 amino acids long and is characterised by four conserved amino acids (three Asp and one His, hence its name). DDHD1 was originally identified as a PA-preferring $\mathrm{PLA}_{1}$ with activity against PI, PC and PE in vitro [51]. However, recent studies confirm that DDHD1 is a PLA 1 for PI and PS based on the lipid profiles of brains from $\mathrm{DDHD}^{-/-}$mice [52]. Analysis of the lipid content from brain tissue from $\mathrm{DDHD}^{-/-}$mice revealed that DDHD1 inactivation causes a substantial decrease in the level of C20:4 lysoPI with a corresponding increase in PI. Genetic and biochemical studies in C.elegans also 
identified a DDHD1 homologue (ipla-1) as a PLA 1 that is involved in the remodelling of the fatty acid at the $s n-1$ position of PI $[50,53]$. Mutation in ipla- 1 caused reduced stearic acid content of PI from $25 \%$ to $6 \%$ with no change in PC, PE or PS.

One of the outstanding questions regarding DDHD1 is whether it is only involved in the remodelling of de novo synthesised PI as suggested above or has additional functions. Hydrolysis of $s n$-1-stearoyl-sn-2-arachidonoyl-PI by DDHD1 could provide $s n$-2arachidonoyl-lysoPI which is a potent activator of the orphan receptor, GPR55 particularly in the brain [54]. Moreover, deleterious mutations in human DDHD1 cause a rare neurological disorder, hereditary spastic paraplegia [52]. This implies that DDHD1 has multiple functions; remodelling of PI after de novo synthesis as well as providing the agonist for the GPR55 receptor.

\subsection{Fatty acid remodelling of Phosphatidylinositol at the sn-2 position by sn1-lysoPI acyltransferase (LPIAT)}

For PI to acquire arachidonic acid at the $s n-2$ position, a lysoPI acyl transferase is required. Recent studies have identified the enzyme, LPIAT (also known as MBOAT7), an integral membrane enzyme at the ER with substrate activity for $s n$-1-acyl-lysoPI $[55,56]$ (see Fig. 5). In mice lacking LPIAT, C18:0/C20:4 PI levels are reduced and moreover there is also an absolute decrease in total PI levels in the brain $[12,44]$. Recovery of homozygotes is less than expected and at E18.5, the forebrain of the LPIAT ${ }^{-/-}$mice is smaller; the cerebral cortex and the hippocampus are specifically reduced in size. LPIAT deficiency causes atrophy of the cerebral cortex and hippocampus and disordered lamination of the cortical layer [44]. It is noteworthy that this phenotype is similar PITP $\alpha / \mathrm{PITP} \beta$ mice where lamination of the 
cortical layer is disrupted ultimately leading to apoptosis [57]. Additionally, neurite outgrowth of hippocampal neurons from the LPIAT knockout mice is reduced in vitro, again like that observed in PITP $\alpha$ knockdown hippocampal neurons [58]. PITP $\alpha / \beta$ are single domain lipid transfer proteins that can bind and transfer PI in vitro $[59,60]$. PITP $\alpha$ prefers to bind PI and PC with shorter acyl chains with the following preference order: 16:1>16:0>18:1>18:0>20:4 [61]. These data would suggest that PITP $\alpha$ prefers to bind newlysynthesised PI rather than the remodelled PI.

In humans, MBOAT7 (LPIAT) is highly expressed in the liver and a variant of MBOAT7 (rs641738 $\mathrm{T}$ allele) has been identified that increases the risk of non-alcoholic fatty liver disease (NAFLD) $[62,63]$. This allele is associated with lower protein expression in the liver and is accompanied by changes in fatty acid composition of PI analysed from plasma. In the liver, MBOAT7 is localised to the ER, MAMs (ER membranes associated with mitochondria) and lipid droplets. This allele also disposes humans to hepatocellular carcinoma [63]. These results suggest that stearoyl arachidonoyl-PI has specific functions in mammalian cells that cannot be fulfilled by other PI species. It is worth noting that the acyl composition of PI in other organisms is not enriched in stearic and arachidonic acids. Dominant PI species in soy is $16: 0 / 18: 2$ [64], yeast is $16: 0 / 18: 1$ and 16:0/16:1 [65]; and in Drosophila, the amino acyl chains in PI are 16:0 (31\%) 16:1 (15\%); 18:1 (22\%) and 18:2 (19\%). No arachidonic acid is present in Drosophila heads [66]. In Dictyostelium discoideum, the major PI species is 16:0 that is ether-linked at sn-1 and $18: 1$, which is acyl-linked at $s n-2$ [67]. One possibility is that in mammalian cells, inositol lipids are a source of bioactive metabolites such as arachidonic acid (for making prostaglandins, leukotrienes etc.), sn-2-arachidonoyl-lysoPI (acting as an agonist for the orphan receptor GPCR55) and the endocannabinoid, 2-arachidonoyl glycerol [68]. The making of these signalling molecules may be one of the key reasons why PI is 
enriched in arachidonic acid. It is interesting to note that of all the tissues, stearoyl arachidonoyl PI is most enriched in brain compared to other tissues at $85 \%$ [11].

\subsection{Fatty acid remodelling of Phosphatidylinositol at the $s n-1$ position by $s n-2$-lysoPI acyltransferase (LYCAT)}

Studies in C.elegans identified three acyltransferases that incorporated stearic acid into the sn1 position of PI $[53,69]$. Mammalian LYCAT was identified as the closest homologue of the C.elegans enzymes. LYCAT was originally identified as a lysocardiolipin acyltransferase in an in vitro assay. Subsequently, LYCAT was shown to exhibit a preference for lysoPI with a preference for incorporating C18:0 at the $s n-1$ position. LYCAT-knockdown mice exhibits a reduction in stearate and an increase in palmitate within PI in various tissues [69]. LYCAT also determines the fatty acid composition of PI in vivo. LYCAT-deficient mice are outwardly healthy and fertile. In the mice, stearoyl-CoA acyltransferase activity toward the $s n-1$ position of PI is reduced, and the fatty acid composition of PI, but not those of other major phospholipids, is altered. Furthermore, expression of mouse LYCAT rescues the phenotype of C. elegans acl-8 acl-9 and acl-10 triple mutants. Thus LYCAT is a determinant of PI molecular species at the $s n-1$ position and its function is conserved in C. elegans and mammals. In PI of the $\mathrm{LYCAT}^{-/-}$liver, the amounts of 18:0/20:4 species is reduced by $27 \%$ and the amounts of 16:0/18:2, 18:0/18:2, 18:1/18:2, and 16:0/20:4 species are increased. The change in PI composition is reflected in $\mathrm{PI}(4) \mathrm{P}$ and $\mathrm{PI}(4,5) \mathrm{P}_{2}$ as well. The extent of 18:0/20:4 species is reduced by $40 \%$ and $50 \%$, respectively, and the amounts of 16:0/18:2, 18:0/18:2, 18:1/18:2, 16:0/20:4, and 16:0/22:6 species increased [69]. Like LPIAT, LYCAT localises to the ER [69], indicating that remodelling of PI takes place here. 
$\mathrm{PI}(4,5) \mathrm{P}_{2}$ and $\mathrm{PI}(3) \mathrm{P}$ play important roles in endocytic traffic and in LYCAT siRNA-treated human ARPE-19 cells clathrin-mediated endocytosis is perturbed. Interestingly, LYCAT silencing selectively perturbed the levels and localisation of $\mathrm{PI}(4,5) \mathrm{P}_{2}$. The acyl chain profile of $\mathrm{PI}(4,5) \mathrm{P}_{2}$ was also altered but not that of PI suggesting that LYCAT remodels the acyl chain of a selective pool of PI which is channelled into $\mathrm{PI}(4,5) \mathrm{P}_{2}$ in this cell-type. As described in Section 5, LYCAT was found to localise extensively with ER-derived PIS vesicles and tubules known to transiently interact with ER-PM contact sites. This would suggest that remodelled PI is transferred to the plasma membrane whilst the bulk of the PI made by PIS in non-tubular ER may not be remodelled [70].

\section{Fatty acyl composition of phosphatidylinositol in Cancer cells}

The hallmark signature of PI lipids in cells from animal tissue is predominantly stearoylarachidonoyl PI, as discussed above. In contrast, analysis of cultured cell-lines of both human and mouse origin reveal that disparate cancer cell lines possess a more varied composition. Transformed cells contain little 1-stearoyl-2-arachidonoyl-PI (C38 carbon); instead PI species have shorter and less saturated acyl chains compared to normal cells (C36 and C34 carbons). Each cell line has a unique fingerprint. Four PI species 38:4, 38:3, 36:2 and 34:1 were the predominant species present in different combinations. The cancer cell lines have a higher level of mono- and di-saturated acyl chains (C36). Fragmentation of the 36 carbon lipids revealed that most of the lipid was 18:1/18:1 suggesting of an increase in the production of oleic acid (18:1). [11]. 
The transformed cells examined above were mutated in p53 (e.g. R172H, R248W, or R273H) leading to gain of function. However, transformed cells, which were p53-null (PC3) or had normal levels (Capan-2) of p53 did not have high levels 36 carbon PI. Importantly, the changes were only observed in PI but not PC. Thus, mutation of p53 rather than loss was responsible for this change. This was confirmed by introducing p53 mutations in MEFs and 12 cell lines were created: 6 controls and 6 mutants. The mutant cell lines had a 50\% increase in C36 carbon mainly 18:1/18:1 [11].

In a separate study, the role of wild type p53 was examined in HCT116 cell line [71]. (This cell line was also used in the previous study and had a predominance of C36 and C34 carbons in their PI lipids [11]). In this study they asked if increases in p53 would affect the acyl chain composition of phospholipids. During cellular stress, levels of the transcription factor p53 are increased and this induces a complex network of many genes to trigger a contextdependent anti-proliferative cellular response including cell cycle arrest, apoptosis, autophagy and senescence [72]. Essentially p53 allows the cells protection from becoming malignant. Increased expression of p53 shifted the fatty acid profile of many phospholipids from di-unsaturated species (e.g. 18:1/18:1) to either saturated or mono-unsaturated. These changes were most prominent in the PI species [71]. The increase in p53 resulted in a decrease in both $\mathrm{PI}(4,5) \mathrm{P}_{2}$ and $\mathrm{PI}(3,4,5) \mathrm{P}_{3}$. PI levels were not determined so it is not clear whether the decrease in $\mathrm{PI}(4,5) \mathrm{P}_{2}$ results from defects in phosphorylation by PI 4-kinase and PIP 5-kinase or due to a drop in PI levels. One of the outcomes of decreased levels of $\mathrm{PI}(4,5) \mathrm{P}_{2}$ resulted in reduced AKT activation. The increase in p53 was found to repress the enzyme, stearoyl CoA desaturase 1 (SCD1). This enzyme is responsible for the biosynthesis of monounsaturated fatty acids (C16:1 and C18:1) from the corresponding preferred substrates, palmitoyl- (C16:0) and stearoyl-CoA (C18:0). Repression of stearoyl CoA desaturase, the 
enzyme that converts saturated to mono-unsaturated fatty acids, causes a shift in the content of phospholipids with mono-unsaturated acyl chains towards more saturated phospholipid species, particularly of the phosphatidylinositol headgroup class. Interestingly addition of oleic acid (18:1) restored the levels of $\mathrm{PI}(4,5) \mathrm{P}_{2}$ and $\mathrm{PI}(3,4,5) \mathrm{P}_{3}$ and AKT phosphorylation [71].

Inhibition of stearoyl CoA desaturase expression by p53 will also result in increases in palmitic acid. The histone deacetylase, SIRT6 interacts with p53 and this interaction increases following palmitic acid treatment [73]. In response to palmitic acid, both p53 and SIRT6 form a complex and bind to the promotors of CDS1 and CDS2, two enzymes required for PI synthesis. Thus, wild type p53 not only switches the acyl chain composition of PI from mono-unsaturated to saturated acyl chains, it also promotes an increase in the enzymes that make CDP-DG, the rate limiting intermediate for PI synthesis.

The way that p53 affects the acyl composition of PI appears to be complex. Whilst wild type p53 appears to affect acyl composition by repressing the enzyme that makes C16:1 and C18:1, mutation of p53 results in loss C38 carbon PI with an increase in C36 PI. Since p53 regulates a vast network of genes downstream, multiple mechanisms must be in play to modulate the acyl composition of PI. Presumably, distinct modulation of the acyl composition of PI in cells mutated with p53 or cells where p53 is increased reflects the differing needs of the cells. Thus it is of interest that mutant p53 is stabilized by binding to type I phosphatidylinositol phosphate 5-kinase $\alpha$ and its product, $\mathrm{PI}(4,5) \mathrm{P}_{2}$ in the nucleus [74]. 


\section{Localisation of PI synthesising enzymes in sub-domains of the ER}

CDS and PIS enzymes, expressed in cultured cell-lines, localise at the ER. The ER is partitioned into sub-domains specialised for different functions including rough and smooth ER and the double membrane of the nuclear envelope. In addition, the ER can be present as flat sheets or dynamic tubules that contact other organelles including mitochondria, plasma membranes and endosomes. The ER also interacts with microtubules to position the ER dynamically. GFP-tagged PIS localises to both in the dynamic ER tubules and in the central perinuclear ER, but is particularly enriched in rapidly moving mobile structures [75]. Interestingly, only the active PIS localises to these mobile structures as the catalytically inactive enzyme failed to partition to the mobile compartment, The formation of these structures is dependent on the cycling of the small GTPase, Sar, from the GDP to GTP form. Sar is the GTP binding proteins required for the formation of COPII vesicles that ferry cargo from the ER to the cis-Golgi. In addition to PIS, Rab10, CEPT1(CEPT1 converts DG to PE and to PC), LYCAT and vacuole membrane protein 1 (VMP-1) localise at the tip of ER tubules during tubule elongation [70, 76, 77].

Vacuole membrane protein 1 (VMP1) is an ER-resident multi-spanning protein first identified for its role in autophagy and more recently, a more general role for VMP1 in regulating membrane contact sites (MCSs) [77]. VMP1 forms ER microdomains in close contact with other organelles such as lipid droplets, autophagosomes and endosomes. In HeLa cells, VMP1 showed a high level of colocalization with the enzymes PIS and CEPT1. About $50 \%$ of PIS and $70 \%$ of CEPT1 puncta co-localized with VMP1 [77]. VMP1 is also detected at the tip of growing ER tubules, thus supporting the possibility that VMP1 may have a role in ER dynamics through the regulation of these ER subdomains. The presence of CEPT1 
and PIS enzymes could reflect local enrichment of PI and choline/ethanolamine-containing phospholipids, thus raising the possibility that VMP1/CEPT1/PIS1/LYCAT domains might function as platforms for the synthesis of phospholipids that are essential for lipid trafficking between organelles.

Co-localization of VMP1 with PIS/LYCAT domains suggests that these domains may be involved in PI trafficking of remodelled PI, and therefore required for the formation of phosphorylated PIs. Previous reports have shown that VMP1 regulates PI(3)P in autophagy. The omegasome is an ER-derived region that organizes the formation of autophagosomes. In this structure, PI is converted to PI(3)P by the class III PI3K enzyme, VPS34. Previous studies have shown that VMP1 co-localizes with the PI-enriched ER-derived omegasome and, in the absence of VMP1, PI(3)P accumulates aberrantly at the ER leading to the formation of small isolation-membrane-like structures. Autophagosomes arise from PIS puncta, and thus it is tempting to speculate that VMP1/PIS puncta may represent contact sites between the ER and the autophagosome membrane, which could facilitate the transfer of PI [78, 79].

The localisation of PIS at these ER subdomains does not coincide with the localisation of CDS enzymes. This raises the question of substrate provision for PIS. CDP-DG is a minor lipid in that it does not accumulate in substantial amounts - it is rapidly metabolised into PI. The lipid would need to be highly mobile and may partition into these ER subdomains by diffusion. The interesting question is: why is it necessary for PIS to partition into these domains or alternatively, why do CDS enzymes not partition into these regions? Further work that examines the endogenous enzymes is needed to confirm that this behaviour is not an artefact of over-expression. 
There are some indications that PIS may be dysfunctional in disease. Increased PIS expression has been associated with oral cancer [80] and recent insights gained from studies on zebrafish have linked ablated expression of the enzyme with the development of hepatic steatosis and inflammation of the intestinal mucosa [81, 82]. Additionally in zebrafish, PIS expression in the eye is required to maintain particular cell populations [83] including photoreceptor and lens epithelial cells; loss-of-function mutations in this enzyme give rise to the opaque lens or cataract phenotype in this organism [83].

\subsection{PI synthesis at the nuclear envelope is restricted by CNEP-1}

Although the ER is contiguous with the nuclear envelope, PI synthesis is apparently restricted to the peripheral and cortical ER. CNEP-1 (CTD nuclear envelope phosphatase 1) is an activator of the PA phosphatase (also known as lipin), which is the metabolic branchpoint between the production of PI and the major membrane lipids, PC and PE (Fig. 3). CNEP-1 localises to the nuclear envelope $[84,85]$ where it activates PA phosphatase to bias phospholipid flux towards PC and PE and to limit PI synthesis. In the absence of CNEP-1, PI levels are increased and causes the formation of ectopic ER sheets in the vicinity of the nucleus that wrap around the nuclear envelope and cause downstream defects in nuclear envelope disassembly. Thus, one mechanism that can determine whether PA is converted to PI or DG is regulated by the presence of lipin enzymes.

\section{Phospholipase $\mathrm{C}$ signalling}


During PLC signalling, the PA formed at the plasma membrane is enriched with stearic acid at $s n-1$ and arachidonic acid at the $s n-2$ position. This composition of PA reflects the fatty acid profile of $\mathrm{PI}(4,5) \mathrm{P}_{2}$. Phospholipase D is often activated at the same time as PLC and the PA formed will reflect the fatty acid profile of PC, the substrate for PLD [86]. Whether these PA species, derived from different sources, are kept separate and enter different metabolic pools at the ER is not well understood. The central dogma has been that the PA derived from phosphorylation of DG derived from PLC-mediated $\mathrm{PI}(4,5) \mathrm{P}_{2}$ hydrolysis is converted into PI thus maintaining the characteristic fatty acid composition of PI [87, 88]. This metabolic bias would go towards enrichment of PI if several enzymes of the $\mathrm{PI}(4,5) \mathrm{P}_{2}$ cycle are selective for C18:0/20:4 acyl chain containing species. Analysis of the composition of PI in platelets after stimulation with thrombin revealed that the fatty acid profile was altered such that the newlysynthesised PI was no longer enriched in stearic and arachidonic acid and was suggested that the de novo synthetic pathway lacks the specificity to produce the characteristic stearate and arachidonate composition of PI [89]. Other studies supported this conclusion (reviewed in [40]). The identification of acyl transferases, LPIAT and LYCAT (see Fig. 5) suggest that enrichment of PI to its characteristic fatty acid composition is achieved by deacylationreacylation cycle and that a closed cycled may not always operate. In other words, the intermediates of the $\mathrm{PI}(4,5) \mathrm{P}_{2}$ cycle are not strictly recycled back to regenerate $\mathrm{PI}(4,5) \mathrm{P}_{2}$ and can exit the cycle [90]. This would necessitate PI to be resynthesised de novo to replace the lost intermediates. In the brain, DG derived from PLC $\beta$-mediated $\mathrm{PI}(4,5) \mathrm{P}_{2}$ hydrolysis is used to make 2-arachidonoyl-glycerol (2-AG), an agonist for endocannabinoid receptors. Two DAG lipases have been identified - DAGL $\alpha$ and DAGL $\beta$ that are responsible for making 2-AG [68].

Furthermore, it has been demonstrated that there are various species of both PI and PA that are not involved within the $\mathrm{PIP}_{2}$ cycle, or at least, not used by the machinery specific for the $\mathrm{PIP}_{2}$ 
cycle. When looking at PA and PI in MEF cells, it was noted that the smaller acyl chained PIs did not exists, i.e. 30:0 and 30:1, even though the same acyl chain composition of PA makes up $21 \%$ of total PA within the cells. The implications being there must be some pools of PA in the ER not involved in the $\mathrm{PIP}_{2}$ cycle, and due to the very short acyl chains on these molecules it is plausible that this PA is, to an extent, purely structural and used to provide stability in regions of positive curvature of the ER, concentrating in the outer monolayer [91].

\subsection{Regulation of CDS enzymes during phospholipase C signalling}

The rate-limiting enzyme in the synthesis of PI is the formation of CDP-DG from PA catalysed by CDS enzymes. During intense PLC signalling, as much at $30-40 \%$ of the PI can be consumed and therefore the amount of CDS activity could dictate how rapidly PI is resynthesised. Studies in Drosophila and zebrafish suggests that CDS activity regulates both the availability of $\mathrm{PI}(4,5) \mathrm{P}_{2}$ and the extent of $\mathrm{PI}(4,5) \mathrm{P}_{2}$-dependent signalling. Drosophila express a single $c d s$ gene and mutation in $c d s$, displays light-induced irreversible loss of phototransduction and retinal degeneration [28]. Phototransduction in photoreceptor cells in flies is dependent on light-activated-Gq-PLC $\beta$ activation and the amplitude of the light response is modulated by Cds levels; Cds-dependent $\mathrm{PI}(4,5) \mathrm{P}_{2}$ recycling limits $\mathrm{PLC}-$ mediated phototransduction $[28,92,93]$. In zebrafish, CDS-dependent phosphoinositide availability limits VEGF-A signalling [25]. Like humans and mice, zebrafish have two CDS genes, $c d s 1$ and $c d s 2$. $C d s 2$ mutants resulted in vascular-specific defects in vivo and this is due to the failure of VEGF-A-stimulated PLC activity; exogenously-added $\mathrm{PI}(4,5) \mathrm{P}_{2}$ rescued the phenotype indicating that CDS2 controlled the supply of $\mathrm{PI}(4,5) \mathrm{P}_{2}$. Experiments done in cultured HUVEC endothelial cell-line found that knockdown of either CDS1 or CDS2 caused defective invasion and reduced ERK activation, an in vitro model for the vascular defects observed in the animals. 
These data indicate that the level of expression of CDS enzymes may be a determining factor in the rapid replenishment of $\mathrm{PI}(4,5) \mathrm{P}_{2}$.

In a recent study in $\mathrm{H} 9 \mathrm{c} 2$ cardiomyoblasts, vasopressin was found to selectively cause an increase in CDS1 but not CDS2 mRNA (Fig. 6). No increase in PIS mRNA was observed. Activation of PKC was required for the increase in CDS1 mRNA, as inhibitors of PKC blocked the response. Moreover, PMA was found to increase CDS1 mRNA. PKC stimulates cFos expression, which was responsible for the increase in CDS1 mRNA [34, 94]. Whilst this study identifies cFos as a regulator of CDS1 mRNA expression (Fig. 6), a previous study reported that an increase in cFos protein can also directly activate CDS1 at the ER [95, 96]. It is likely that $\mathrm{cFos}$ can associate itself to the ER in an amphitropic manner, providing a platform for physical interaction between cFos and CDS1. The N-terminal domain of cFos was found to be responsible for interaction with CDS1, but lipid synthesis was only promoted in vitro when the binding domain ( $\mathrm{K}^{139}$ to $\mathrm{R}^{159}$ ) of cFos was present, with $\mathrm{R}^{146}$ being the crucial residue for CDS1 activation by cFos. It is also noteworthy that lipid synthesis was not activated by cJun, another prominent component of the AP-1 complexes [96].

Other studies have also observed regulation of CDS1 and CDS2 but by different mechanisms. In PGC- $1 \alpha / \beta$ heart-specific knockout mice, there is a decrease in CDS1 mRNA expression but an increase in CDS2 mRNA. Vice versa, expression of PGC- $1 \alpha$ or $-1 \beta$ increased CDS1 mRNA in neonatal rat cardiac myocytes [97]. ERR (estrogen-related receptor) is a well-characterised PGC-1 $\alpha$ co-activator target [98] and two conserved ERR binding site sequences present at the CDS1 promoter region was found to be responsible for PGC-1 $\alpha$-dependent activation. Yet another regulator is ZEB1, an E-Box transcriptional repressor [99]. The expression of CDS1 
mRNA was found to be inversely correlated with ZEB1 in a series of 22 NSCLC (non-small cell lung cancer) cell-lines. This result was confirmed by over-expression of ZEB1 in H358 cells where a decrease in CDS1 mRNA was noted whilst knockdown of ZEB1 resulted in increased CDS1 mRNA expression. As described previously in Section 4, analysis of the fatty acid composition of PI from a variety of cultured cell lines indicate a variable amount of enrichment in stearoyl-arachidonoyl PI and moreover, mutation in p53 results in PI that contains reduced length fatty acid moieties [11]. Interestingly, p53 together with SIRT6 has been found to be responsible for the increase in both CDS1 and CDS2 mRNA when cells were treated with palmitic acid for $16 \mathrm{~h}$. Co-occupancy of p53 and SIRT6 on CDS1 and CDS2 promoters were responsible for increased gene expression [73]. Palmitic acid is known to cause ER stress [100]. In Table 2, we summarize the regulation of CDS enzymes. It is clear that PI synthesis is a regulated process through transcriptional regulation of CDS genes.

\section{Future Directions}

Our knowledge of the enzymes required for the synthesis of PI and its subsequent remodelling to acquire its characteristic acyl chain composition is well understood in mammalian cells. However, several outstanding questions remain. Future studies need to focus on the significance of the acyl chain remodelling of PI and why is this altered in cancer? Although phosphoinositides are a source of metabolites such as sn-2-arachidonyl-lysoPI, and 2arachidonoyl glycerol, what is of note is that the absolute levels of PI are decreased when PI is unable to acquire arachidonic acid at the $s n-2$ positon? This raises elementary questions. What determines how much PI is produced in cells? Why is this synthesis limited to 5-10\%? Early studies suggested that PI synthase activity is inhibited by $1 \mathrm{mM}$ PI in vitro [101], thus feedback regulation is one potential mechanism. Another being the tight regulation of CDS enzymes: the 
level of PI production will also be dependent on the availability of CDP-DG. The plethora of proteins that promote or suppress CDS levels at the transcriptional level must also have some effect on the levels and limits of PI.

One of the most intriguing findings is the localisation of the PIS in the subdomain of the ER together with other lipid metabolising enzymes such as CEPT1 and LYCAT. What determines this localisation and what is its significance? How does it obtain the substrate CDP-DG for conversion to PI? Is the transfer of PI to other compartments taking place from these dynamic structures? To answer these questions, methods need to be developed for studying phosphatidylinositol localisation in living cells and tracking its movements from its site of synthesis to other organelles. Hopefully, future advances will remedy this situation.

\section{Acknowledgements}

We would like to thank British Heart Foundation for funding. This work was supported by grants from British Heart Foundation, Grant numbers FS/15/73/31672 and FS/12/49/29729. 


\section{Fig. 1 Phosphatidylinositol structure.}

Phosphatidylinositol comprises of a glycerol backbone (black box), two acyl chains, $\mathrm{R}_{1}$ and $\mathrm{R}_{2}$ at the $s n-1$ and $s n-2$ positions (red and green box respectively), a phosphate at the $s n-3$ position (blue box) and an inositol headgroup (orange box). The hydroxyls at position 3, 4, and 5 are phosphorylated either singly or at multiple sites, which yields seven unique phosphorylated species of PI. The synthesis of PI takes place at the ER whilst the production of the phosphorylated species occurs at other organelles including the plasma membrane.

\section{Fig. 2 Synthesis of PI de novo and during the $\mathrm{PI}(4,5) \mathrm{P}_{2}$ cycle}

At the ER, de novo synthesis of PI begins with G-3-P acylated by GPAT enzymes at the sn-1 position followed by a second acylation at the $s n-2$ position by LPAAT enzymes to PA. PA and CTP are converted to CDP-DG catalysed by CDS enzymes (CDS1 and CDS2). In the final step, inositol and CDP-DG are synthesised into PI catalysed by the enzyme, PI synthase (PIS). PI resynthesis also occurs following stimulation of PLC at the plasma membrane. Phospholipase $\mathrm{C}$ hydrolyses of $\mathrm{PI}(4,5) \mathrm{P}_{2}$ resulting in the formation of the second messengers, $\mathrm{IP}_{3}$ and DG. DG is phosphorylated to PA at the plasma membrane by DG kinase (DGK). PA is also directly produced from PC by phospholipase D. At the ER, PA is resynthesized into PI using the same enzymes of the de novo pathway. The newly-synthesised PI is transferred to the plasma membrane for phosphorylation to $\mathrm{PI}(4,5) \mathrm{P}_{2}$ by the resident enzymes, PI4KIII $\alpha$ and PIP5K. Transfer of PI and PA between membranes is carried out by lipid transfer proteins, in particular members of the PITP family. Abbreviations: G-3-P, glycerol-3-phosphate; PI, phosphatidylinositol; PITPs, phosphatidylinositol transfer proteins; PI4P, PI 4-phosphate; $\mathrm{PI}(4,5) \mathrm{P}_{2}$, phosphatidylinositol (4,5) bisphosphate; PLC, phospholipase C; DG, diacylglycerol; PA, phosphatidic acid; $\mathrm{IP}_{3}$, inositol $(1,4,5)$ triphosphate, CDS, CDP-DG synthase; PIS, PI 
synthase; GPAT, Glycerol phosphate acyl transferase; LPAAT, LysoPA acyl transferase; PLD, phospholipase D;

Fig. 3 PA is converted either into PI or into DG at the ER or to cardiolipin in mitochondria

At the ER, newly-synthesised PA can either be converted into CDP-DG by CDS1/2 for the synthesis of PI or can be converted into DG by PA phosphatases (PAP). DG can be converted into triacylglycerol (TG), or converted into the major phospholipids, PC and PE. CNEP-1 activates lipin at the nuclear envelope, biasing the conversion of PA to DG towards PC synthesis. In mitochondria, PA is converted into CDP-DG by the mitochondrial-localised enzyme, TAMM41 into phosphatidylglycerophosphate (PGP). PGP is dephosphorylated to phosphatidylglycerol (PG) which is the substrate for cardiolipin synthase (CLS) to make cardiolipin. Abbreviations as in Fig. 2. CNEP-1, C-terminal domain nuclear envelope phosphatase-1;

\section{Fig. 4 Distinct CDS enzymes localise to the ER and mitochondria}

[A] Three CDS enzymes, CDS1, CDS2 and TAMM41, are present in the mammalian genome. Domain structure of the CDS enzymes, CDS1, CDS2 based on the structure of the bacterial enzyme, Thermotoga maritama, TmCdsA, and the structurally-unrelated CDS enzyme, TAMM41 containing the MMP37 domain (MMP37, mitochondrial matrix proteins of $37 \mathrm{kDa}$; PFAM: 09139). The transmembrane domains of CDS1 and CDS2 are shown in coloured boxes. Blue box, N-terminal domain, green boxes, middle domain, which is the dimerization interface, and the orange boxes that comprise the highly-conserved C-terminal domain. 
[B] Cartoon representation of CDS1 and CDS2 based on the three dimensional structure of TmCdsA dimer. The monomers are coloured red and yellow. TAMM41 is shown as a peripheral membrane protein.

[C] Localisation of CDS1 and CDS2 at the ER and TAMM41 in the inner mitochondrial membrane. TAMM41 is a peripheral protein localised to the inner mitochondrial membrane.

Fig. 5 Remodelling of de novo-synthesised PI to acquire its specific fatty acid composition by phospholipase A and acyl transferases.

De novo synthesised PI is remodelled at the ER. De novo synthesised PI mainly contains saturated and mono-saturated acyl chains, which are replaced through deacylation and reacylation reactions. PI is first deacylated by a phospholipase $\mathrm{A}_{1}\left(\mathrm{PLA}_{1}\right)$ or $\mathrm{A}_{2}\left(\mathrm{PLA}_{2}\right)$ yielding $s n-1$ lysoPI or $s n-2$ lysoPI. LysoPI's are reacylated by acyltransferases, LYCAT or LPIAT, that use specific acyl-CoAs.

Fig. 6 Regulation of CDS1 mRNA by protein kinase and cFos during the PI(4,5) $\mathrm{P}_{2}$ cycle Activation of phospholipase $\mathrm{C}$ by G-protein-coupled receptors hydrolyses $\mathrm{PI}(4,5) \mathrm{P}_{2}$ to generate diacylglycerol (DG). DG activates protein kinase $\mathrm{C}$ that stimulates the increase in cFos. cFos increases the expression of CDS1 mRNA. The increase in CDS1 enzyme would facilitate the resynthesis of $\mathrm{PI}$ to provide substrate for $\mathrm{PI}(4,5) \mathrm{P}_{2}$ resynthesis at the plasma membrane. VP, vasopressin; $\mathrm{V}_{1} \mathrm{R}$, vasopressin receptor; 
Table 1 Enzymes at the ER involved in PI synthesis and acyl chain remodelling in mammals

\begin{tabular}{|c|c|c|c|c|}
\hline Enzymes & Alt names & Enzyme reaction & $\begin{array}{l}\text { Acyl-CoA } \\
\text { specificity }\end{array}$ & References \\
\hline GPAT3, & & G-3-P to LPA & unknown & {$[13]$} \\
\hline GPAT4 & & G-3-P to LPA & unknown & [13] \\
\hline LPAAT $1,2,3,4,5$ & $\begin{array}{l}\text { AGPAT } 1 \\
\text { LPAAT } \alpha, \beta, \gamma, \delta, \varepsilon\end{array}$ & LPA to PA & Various & {$[15]$} \\
\hline CDS1 & & PA to CDP-DG & & [22] \\
\hline CDS2 & & PA to CDP-DG & & [33] \\
\hline PIS & & CDP-DG to PI & none & {$[43]$} \\
\hline LPIAT & MBOAT7 & LPI to PI & $\begin{array}{l}\text { C20:4-CoA at } \\
s n-2\end{array}$ & {$[12]$} \\
\hline LYCAT & $\begin{array}{l}\text { AGPAT8, } \\
\text { ALCAT1, LYCAT1 }\end{array}$ & LPI to PI & $\begin{array}{l}\mathrm{C} 18: \mathrm{O}-\mathrm{CoA} \\
\text { at } s n-1\end{array}$ & [69] \\
\hline DDHD1 & & PI to $s n-2$ lysoPI & & {$[50,52]$} \\
\hline $\mathrm{PLA}_{2}$ & & PI to $s n-1$ lysoPI & & [49] \\
\hline
\end{tabular}


Table 1: Regulation of CDS1 and CDS2 mRNA by different mechanisms.

\begin{tabular}{|l|l|l|l|l|}
\hline Treatment & $\begin{array}{l}\text { Up- } \\
\text { regulated }\end{array}$ & $\begin{array}{l}\text { Down- } \\
\text { regulated }\end{array}$ & Comments & References \\
\hline Vasopressin & $C D S 1$ & $\begin{array}{l}\text { H9c2 cells stimulated for 16 h. } \\
\text { CDS1 expression inhibited by } \\
\text { PKC and AP-1 inhibitor }\end{array}$ & {$[34]$} \\
\hline PMA & $C D S 1$ & & H9c2 cells stimulated for 24 h. & {$[34]$} \\
\hline $\begin{array}{l}\text { PGC-1 } \alpha / \beta \\
\text { heart-specific } \\
\text { knockout mice }\end{array}$ & $C D S 2$ & $C D S 1$ & $\begin{array}{l}\text { Gene expression profiling } \\
\text { revealed reduced expression of } \\
\text { CDS1 }\end{array}$ & {$[97]$} \\
\hline $\begin{array}{l}\text { PGC-1 } \alpha \text { or } \\
\text { PGC-1 } \beta \text { over- } \\
\text { expression }\end{array}$ & $C D S 1$ & $\begin{array}{l}\text { Over-expression in Neonatal rat } \\
\text { cardiac myocytes }\end{array}$ & {$[97]$} \\
\hline $\begin{array}{l}\text { Palmitic acid } \\
\text { via p53 with } \\
\text { SIRT6 }\end{array}$ & $\begin{array}{l}C D S 1 \\
\text { and }\end{array}$ & & $\begin{array}{l}\text { p53 and SIRT6 bind the } \\
\text { promoters of CDS1 and CDS2 }\end{array}$ & {$[73]$} \\
\hline $\begin{array}{l}\text { Adipocyte } \\
\text { differentiation }\end{array}$ & $C D S 1$ & $\begin{array}{l}\text { 3T3-L1-preadipocytes } \\
\text { differentiated in vitro for 8 days }\end{array}$ & {$[35]$} \\
\hline $\begin{array}{l}\text { Low ZEB1 } \\
\text { expression }\end{array}$ & $C D S 1$ & $\begin{array}{l}\text { 22 NSCLC cell-lines } \\
\text { expressing low ZEB1 have a } \\
\text { high level of CDS1 mRNA }\end{array}$ & {$[99]$} \\
\hline $\begin{array}{l}\text { ZEB1 over- } \\
\text { expression }\end{array}$ & CDS1 & $\begin{array}{l}\text { Cells expressing ZEB1 at high } \\
\text { levels correlated with low } \\
\text { CDS1 levels. }\end{array}$ & {$[99]$} \\
\hline
\end{tabular}




\section{References}

[1] T. Balla, Phosphoinositides: tiny lipids with giant impact on cell regulation, Physiol Rev, 93 (2013) 1019-1137.

[2] E.J. Dickson, B. Hille, Understanding phosphoinositides: rare, dynamic, and essential membrane phospholipids, Biochemical Journal, 476 (2019) 1-23.

[3] B. Hille, E.J. Dickson, M. Kruse, O. Vivas, B.C. Suh, Phosphoinositides regulate ion channels, Biochim. Biophys. Acta, 1851 (2015) 844-856.

[4] K. Tsujita, T. Itoh, Phosphoinositides in the regulation of actin cortex and cell migration, Biochim Biophys Acta, 1851 (2015) 824-831.

[5] K.O. Schink, K.-W. Tan, H. Stenmark, Phosphoinositides in Control of Membrane Dynamics, Annual Review of Cell and Developmental Biology, 32 (2016) 143-171.

[6] C.H. Choy, B.-K. Han, R.J. Botelho, Phosphoinositide Diversity, Distribution, and Effector Function: Stepping Out of the Box, BioEssays, 39 (2017) 1700121.

[7] G. Kadamur, E.M. Ross, Mammalian phospholipase C, Annu. Rev. Physiol, 75 (2013) 127-154.

[8] Y. Nakamura, K. Fukami, Regulation and physiological functions of mammalian phospholipase C, J Biochem, 161 (2017) 315-321.

[9] T.D. Bunney, M. Katan, PLC regulation: emerging pictures for molecular mechanisms, Trends Biochem Sci, 36 (2011) 88-96.

[10] A. Mujalli, G. Chicanne, J. Bertrand-Michel, F. Viars, L. Stephens, P. Hawkins, J. Viaud, F. Gaitslacovoni, S. Severin, M.P. Gratacap, A.D. Terrisse, B. Payrastre, Profiling of phosphoinositide molecular species in human and mouse platelets identifies new species increasing following stimulation, Biochim Biophys Acta, 1863 (2018) 1121-1131.

[11] A. Naguib, G. Bencze, D.D. Engle, Chio, II, T. Herzka, K. Watrud, S. Bencze, D.A. Tuveson, D.J. Pappin, L.C. Trotman, p53 mutations change phosphatidylinositol acyl chain composition, Cell Rep, 10 (2015) 8-19.

[12] K.E. Anderson, A. Kielkowska, T.N. Durrant, V. Juvin, J. Clark, L.R. Stephens, P.T. Hawkins, Lysophosphatidylinositol-acyltransferase-1 (LPIAT1) is required to maintain physiological levels of Ptdlns and PtdInsP(2) in the mouse, PLoS. ONE, 8 (2013) e58425.

[13] H. Shindou, T. Shimizu, Acyl-CoA:lysophospholipid acyltransferases, J Biol. Chem, 284 (2009) 1-5. [14] R.E. Gimeno, J. Cao, Thematic Review Series: Glycerolipids. Mammalian glycerol-3-phosphate acyltransferases: new genes for an old activity, Journal of Lipid Research, 49 (2008) 2079-2088.

[15] R.M. Bradley, R.E. Duncan, The lysophosphatidic acid acyltransferases (acylglycerophosphate acyltransferases) family: one reaction, five enzymes, many roles, Current Opinion in Lipidology, 29 (2018) $110-115$.

[16] D. Hishikawa, T. Hashidate, T. Shimizu, H. Shindou, Diversity and function of membrane glycerophospholipids generated by the remodeling pathway in mammalian cells, J Lipid Res, 55 (2014) 799-807.

[17] R.M. Bradley, P.M. Marvyn, J.J. Aristizabal Henao, E.B. Mardian, S. George, M.G. Aucoin, K.D. Stark, R.E. Duncan, Acylglycerophosphate acyltransferase 4 (AGPAT4) is a mitochondrial lysophosphatidic acid acyltransferase that regulates brain phosphatidylcholine, phosphatidylethanolamine, and phosphatidylinositol levels, Biochim Biophys Acta, 1851 (2015) 1566-1576.

[18] A. Triebl, M. Trotzmuller, A. Eberl, P. Hanel, J. Hartler, H.C. Kofeler, Quantitation of phosphatidic acid and lysophosphatidic acid molecular species using hydrophilic interaction liquid chromatography coupled to electrospray ionization high resolution mass spectrometry, J Chromatogr A, 1347 (2014) 104-110.

[19] Y. Nakagawa, B. Rustow, H. Rabe, D. Kunze, K. Waku, The de novo synthesis of molecular species of phosphatidylinositol from endogenously labeled CDP diacylglycerol in alveolar macrophage microsomes, Arch Biochem Biophys, 268 (1989) 559-566. 
[20] S.L. Inglis-Broadgate, L. Ocaka, R. Banerjee, M. Gaasenbeek, J.P. Chapple, M.E. Cheetham, B.J. Clark, D.M. Hunt, S. Halford, Isolation and characterization of murine Cds (CDP-diacylglycerol synthase) 1 and 2, Gene, 356 (2005) 19-31.

[21] S. Halford, K.S. Dulai, S.C. Daw, J. Fitzgibbon, D.M. Hunt, Isolation and chromosomal localization of two human CDP-diacylglycerol synthase (CDS) genes, Genomics, 54 (1998) 140-144.

[22] S. Saito, K. Goto, A. Tonosaki, H. Kondo, Gene cloning and characterization of CDP-diacylglycerol synthase from rat brain, J. Biol. Chem, 272 (1997) 9503-9509.

[23] A. Lykidis, P.D. Jackson, C.O. Rock, S. Jackowski, The role of CDP-diacylglycerol synthase and phosphatidylinositol synthase activity levels in the regulation of cellular phosphatidylinositol content, J. Biol. Chem, 272 (1997) 33402-33409.

[24] A. Lykidis, Comparative genomics and evolution of eukaryotic phospholipid biosynthesis, Prog. Lipid Res, 46 (2007) 171-199.

[25] W. Pan, V.N. Pham, A.N. Stratman, D. Castranova, M. Kamei, K.R. Kidd, B.D. Lo, K.M. Shaw, J. Torres-Vazquez, C.M. Mikelis, J.S. Gutkind, G.E. Davis, B.M. Weinstein, CDP-diacylglycerol synthasecontrolled phosphoinositide availability limits VEGFA signaling and vascular morphogenesis, Blood, 120 (2012) 489-498.

[26] T. Icho, C.P. Sparrow, C.R. Raetz, Molecular cloning and sequencing of the gene for CDPdiglyceride synthetase of Escherichia coli, J Biol. Chem, 260 (1985) 12078-12083.

[27] H. Shen, P.N. Heacock, C.J. Clancey, W. Dowhan, The CDS1 gene encoding CDP-diacylglycerol synthase in Saccharomyces cerevisiae is essential for cell growth, J Biol. Chem, 271 (1996) 789-795. [28] L. Wu, B. Niemeyer, N. Colley, M. Socolich, C.S. Zuker, Regulation of PLC-mediated signalling in vivo by CDP-diacylglycerol synthase, Nature, 373 (1995) 216-222.

[29] X. Liu, Y. Yin, J. Wu, Z. Liu, Structure and mechanism of an intramembrane liponucleotide synthetase central for phospholipid biosynthesis, Nat. Commun, 5 (2014) 4244.

[30] N.J. Blunsom, E. Gomez-Espinosa, T.G. Ashlin, S. Cockcroft, Mitochondrial CDP-diacylglycerol synthase activity is due to the peripheral protein, TAMM41 and not due to the integral membrane protein, CDP-diacylglycerol synthase 1, Biochim Biophys Acta, 1863 (2017) 284-298.

[31] A.Y. Mok, G.E. McDougall, W.C. McMurray, CDP-diacylglycerol synthesis in rat liver mitochondria, FEBS Lett, 312 (1992) 236-240.

[32] Y. Tamura, Y. Harada, S.I. Nishikawa, K. Yamano, M. Kamiya, T. Shiota, T. Kuroda, O. Kuge, H. Sesaki, K. Imai, K. Tomii, T. Endo, Tam41 Is a CDP-Diacylglycerol Synthase Required for Cardiolipin Biosynthesis in Mitochondria, Cell Metab, 17 (2013) 1-10.

[33] K. D'Souza, Y.J. Kim, T. Balla, R.M. Epand, Distinct Properties of the Two Isoforms of CDPDiacylglycerol Synthase, Biochemistry, 53 (2014) 7358-7367.

[34] N.J. Blunsom, E. Gomez-Espinosa, T.G. Ashlin, S. Cockcroft, Sustained phospholipase C stimulation of $\mathrm{H} 9 \mathrm{c} 2$ cardiomyoblasts by vasopressin induces an increase in CDP-diacylglycerol synthase 1 (CDS1) through protein kinase C and cFOS, Biochim Biophys Acta- Molecular and Cell Biology of Lipids, (2019).

[35] Y. Qi, T.S. Kapterian, X. Du, Q. Ma, W. Fei, Y. Zhang, X. Huang, I.W. Dawes, H. Yang, CDPdiacylglycerol synthases regulate the growth of lipid droplets and adipocyte development, J Lipid Res, 57 (2016) 767-780.

[36] Y. He, C. Yam, K. Pomraning, J.S. Chin, J.Y. Yew, M. Freitag, S. Oliferenko, Increase in cellular triacylglycerol content and emergence of large ER-associated lipid droplets in the absence of CDP-DG synthase function, Mol. Biol. Cell, 25 (2014) 4083-4095.

[37] W. Fei, G. Shui, Y. Zhang, N. Krahmer, C. Ferguson, T.S. Kapterian, R.C. Lin, I.W. Dawes, A.J. Brown, P. Li, X. Huang, R.G. Parton, M.R. Wenk, T.C. Walther, H. Yang, A role for phosphatidic acid in the formation of "supersized" lipid droplets, PLoS. Genet, 7 (2011) e1002201.

[38] B. Laurinyecz, M. Peter, V. Vedelek, A.L. Kovacs, G. Juhasz, P. Maroy, L. Vigh, G. Balogh, R. Sinka, Reduced expression of CDP-DAG synthase changes lipid composition and leads to male sterility in Drosophila, Open Biol, 6 (2016) 50169. 
[39] Y. Liu, W. Wang, G. Shui, X. Huang, CDP-diacylglycerol synthetase coordinates cell growth and fat storage through phosphatidylinositol metabolism and the insulin pathway, PLoS. Genet, 10 (2014) e1004172.

[40] B.J. Holub, Metabolism and function of myo-inositol and inositol phospholipids, Annu Rev Nutr, 6 (1986) 563-597.

[41] C. Lofke, T. Ischebeck, S. Konig, S. Freitag, I. Heilmann, Alternative metabolic fates of phosphatidylinositol produced by phosphatidylinositol synthase isoforms in Arabidopsis thaliana, Biochem J, 413 (2008) 115-124.

[42] O.B. Clarke, D. Tomasek, C.D. Jorge, M.B. Dufrisne, M. Kim, S. Banerjee, K.R. Rajashankar, L. Shapiro, W.A. Hendrickson, H. Santos, F. Mancia, Structural basis for phosphatidylinositol-phosphate biosynthesis, Nat Commun, 6 (2015) 8505.

[43] K. D'Souza, R.M. Epand, The phosphatidylinositol synthase-catalyzed formation of phosphatidylinositol does not exhibit acyl chain specificity, Biochemistry, 54 (2015) 1151-1153. [44] H.C. Lee, T. Inoue, J. Sasaki, T. Kubo, S. Matsuda, Y. Nakasaki, M. Hattori, F. Tanaka, O. Udagawa, N. Kono, T. Itoh, H. Ogiso, R. Taguchi, M. Arita, T. Sasaki, H. Arai, LPIAT1 regulates arachidonic acid content in phosphatidylinositol and is required for cortical lamination in mice, Mol. Biol. Cell, 23 (2012) 4689-4700.

[45] C.A. Rouzer, P.T. Ivanova, M.O. Byrne, H.A. Brown, L.J. Marnett, Lipid profiling reveals glycerophospholipid remodeling in zymosan-stimulated macrophages, Biochemistry, 46 (2007) 60266042.

[46] A. Traynor-Kaplan, M. Kruse, E.J. Dickson, G. Dai, O. Vivas, H. Yu, D. Whittington, B. Hille, Fattyacyl chain profiles of cellular phosphoinositides, Biochimica et Biophysica Acta (BBA) - Molecular and Cell Biology of Lipids, 1862 (2017) 513-522.

[47] B.J. Holub, A. Kuksis, Differential distribution of orthophosphate- $32 \mathrm{P}$ and glycerol- $14 \mathrm{C}$ among molecular species of phosphatidylinositols of rat liver in vivo, J. Lipid Res, 12 (1971) 699-705.

[48] M.G. Luthra, A. Sheltawy, The metabolic turnover of molecular species of phosphatidylinositol and its precursor phosphatidic acid in guinea-pig cerebral hemispheres, J Neurochem, 27 (1976) 1501-1511.

[49] J.E. Burke, E.A. Dennis, Phospholipase A2 structure/function, mechanism, and signaling, Journal of Lipid Research, 50 (2009) S237-S242.

[50] K. Tani, T. Kogure, H. Inoue, The intracellular phospholipase A1 protein family, BioMolecular Concepts, 3 (2012) 471.

[51] H.N. Higgs, M.H. Han, G.E. Johnson, J.A. Glomset, Cloning of a phosphatidic acid-preferring phospholipase A1 from bovine testis, J. Biol Chem, 273 (1998) 5468-5477.

[52] J.M. Inloes, H. Jing, B.F. Cravatt, The Spastic Paraplegia-Associated Phospholipase DDHD1 Is a Primary Brain Phosphatidylinositol Lipase, Biochemistry, 57 (2018) 5759-5767.

[53] R. Imae, T. Inoue, M. Kimura, T. Kanamori, N.H. Tomioka, E. Kage-Nakadai, S. Mitani, H. Arai, Intracellular phospholipase A1 and acyltransferase, which are involved in Caenorhabditis elegans stem cell divisions, determine the sn-1 fatty acyl chain of phosphatidylinositol, Mol Biol Cell, 21 (2010) 3114-3124.

[54] M. Alhouayek, J. Masquelier, G.G. Muccioli, Lysophosphatidylinositols, from Cell Membrane Constituents to GPR55 Ligands, Trends in Pharmacological Sciences, 39 (2018) 586-604.

[55] A. Yamashita, M. Watanabe, K. Sato, T. Miyashita, T. Nagatsuka, H. Kondo, N. Kawagishi, H. Nakanishi, R. Kamata, T. Sugiura, K. Waku, Reverse Reaction of Lysophosphatidylinositol Acyltransferase: Functional reconstitution of coenzyme A-dependent transacylation system J. Biol. Chem., 278 (2003) 30382-30393.

[56] A. Caddeo, O. Jamialahmadi, G. Solinas, A. Pujia, R.M. Mancina, P. Pingitore, S. Romeo, MBOAT7 is anchored to endomembranes by six transmembrane domains, Journal of Structural Biology, 206 (2019) 349-360.

[57] Z. Xie, S.K. Hur, L. Zhao, C.S. Abrams, V.A. Bankaitis, A Golgi Lipid Signaling Pathway Controls Apical Golgi Distribution and Cell Polarity during Neurogenesis, Dev Cell, 44 (2018) 725-740 e724. 
[58] K.E. Cosker, S. Shadan, M. van Diepen, C. Morgan, M. Li, V. Allen-Baume, C. Hobbs, P. Doherty, S. Cockcroft, B.J. Eickholt, Regulation of PI3K signalling by the phosphatidylinositol transfer protein PITP\{alpha\} during axonal extension in hippocampal neurons, J. Cell Sci, 121 (2008) 796-803.

[59] S. Cockcroft, The diverse functions of phosphatidylinositol transfer proteins, Curr. Top. Microbiol. Immunol, 362 (2012) 185-208.

[60] S. Cockcroft, N. Carvou, Biochemical and biological functions of class I phosphatidylinositol transfer proteins, Biochim. Biophys Acta, 1771 (2007) 677-691.

[61] A.N. Hunt, A. Skippen, G. Koster, A.D. Postle, S. Cockcroft, Acyl chain-based molecular selectivity for HL60 cellular phosphatidylinositol and of phosphatidylcholine by phosphatidylinositol transfer protein $\alpha$, Biochim Biophys Acta, 1686 (2004) 50-60.

[62] R.M. Mancina, P. Dongiovanni, S. Petta, P. Pingitore, M. Meroni, R. Rametta, J. Boren, T. Montalcini, A. Pujia, O. Wiklund, G. Hindy, R. Spagnuolo, B.M. Motta, R.M. Pipitone, A. Craxi, S. Fargion, V. Nobili, P. Kakela, V. Karja, V. Mannisto, J. Pihlajamaki, D.F. Reilly, J. Castro-Perez, J. Kozlitina, L. Valenti, S. Romeo, The MBOAT7-TMC4 Variant rs641738 Increases Risk of Nonalcoholic Fatty Liver Disease in Individuals of European Descent, Gastroenterology, 150 (2016) 1219-1230 e1216.

[63] P.K. Luukkonen, Y. Zhou, T. Hyotylainen, M. Leivonen, J. Arola, M. Orho-Melander, M. Oresic, H. Yki-Jarvinen, The MBOAT7 variant rs641738 alters hepatic phosphatidylinositols and increases severity of non-alcoholic fatty liver disease in humans, J Hepatol, 65 (2016) 1263-1265.

[64] J.J. Myher, A. Kuksis, Molecular species of plant phosphatidylinositol with selective cytotoxicity towards tumor cells, Biochim Biophys Acta, 795 (1984) 85-90.

[65] R. Schneiter, B. Brugger, R. Sandhoff, G. Zellnig, A. Leber, M. Lampl, K. Athenstaedt, C. Hrastnik, S. Eder, G. Daum, F. Paltauf, F.T. Wieland, S.D. Kohlwein, Electrospray ionization tandem mass spectrometry (ESI-MS/MS) analysis of the lipid molecular species composition of yeast subcellular membranes reveals acyl chain-based sorting/remodeling of distinct molecular species en route to the plasma membrane, J Cell Biol, 146 (1999) 741-754.

[66] T. Yoshioka, H. Inoue, T. Kasama, Y. Seyama, S. Nakashima, Y. Nozawa, Y. Hotta, Evidence that arachidonic acid is deficient in phosphatidylinositol of Drosophila heads, J. Biochem. Japan, 98 (1985) 657-662.

[67] J. Clark, R.R. Kay, A. Kielkowska, I. Niewczas, L. Fets, D. Oxley, L.R. Stephens, P.T. Hawkins, Dictyostelium uses ether-linked inositol phospholipids for intracellular signalling, EMBO J, 33 (2014) 2188-2200.

[68] N. Murataeva, A. Straiker, K. Mackie, Parsing the players: 2-arachidonoylglycerol synthesis and degradation in the CNS, British Journal of Pharmacology, 171 (2014) 1379-1391.

[69] R. Imae, T. Inoue, Y. Nakasaki, Y. Uchida, Y. Ohba, N. Kono, H. Nakanishi, T. Sasaki, S. Mitani, H. Arai, LYCAT, a homologue of C. elegans acl-8, acl-9, and acl-10, determines the fatty acid composition of phosphatidylinositol in mice, J Lipid Res, 53 (2012) 335-347.

[70] L.N. Bone, R.M. Dayam, M. Lee, N. Kono, G.D. Fairn, H. Arai, R.J. Botelho, C.N. Antonescu, J. York, The acyltransferase LYCAT controls specific phosphoinositides and related membrane traffic, Molecular Biology of the Cell, 28 (2017) 161-172.

[71] N. Rueda-Rincon, K. Bloch, R. Derua, R. Vyas, A. Harms, T. Hankemeier, N.A. Khan, J. Dehairs, M. Bagadi, M.M. Binda, E. Waelkens, J.C. Marine, J.V. Swinnen, p53 attenuates AKT signaling by modulating membrane phospholipid composition, Oncotarget, 6 (2015) 21240-21254.

[72] R.M. Elledge, W.-H. Lee, Life and death by P53, BioEssays, 17 (1995) 923-930.

[73] M. Li, T. Hou, T. Gao, X. Lu, Q. Yang, Q. Zhu, Z. Li, C. Liu, G. Mu, G. Liu, Y. Bao, H. Wen, L. Wang, H. Wang, Y. Zhao, W. Gu, Y. Yang, W.-G. Zhu, p53 cooperates with SIRT6 to regulate cardiolipin de novo biosynthesis, Cell Death \& Disease, 9 (2018) 941.

[74] S. Choi, M. Chen, V.L. Cryns, R.A. Anderson, A nuclear phosphoinositide kinase complex regulates p53, Nat Cell Biol, (2019). 
[75] Y.J. Kim, M.L. Guzman-Hernandez, T. Balla, A highly dynamic ER-derived phosphatidylinositolsynthesizing organelle supplies phosphoinositides to cellular membranes, Dev Cell, 21 (2011) 813824.

[76] A.R. English, G.K. Voeltz, Rab10 GTPase regulates ER dynamics and morphology, Nat. Cell Biol, 15 (2013) 169-178.

[77] L.C. Tabara, J.J. Vicente, J. Biazik, E.L. Eskelinen, O. Vincent, R. Escalante, Vacuole membrane protein 1 marks endoplasmic reticulum subdomains enriched in phospholipid synthesizing enzymes and is required for phosphoinositide distribution, Traffic, 19 (2018) 624-638.

[78] T. Nishimura, N. Mizushima, The ULK complex initiates autophagosome formation at phosphatidylinositol synthase-enriched ER subdomains, Autophagy, 13 (2017) 1795-1796. [79] T. Nishimura, N. Tamura, N. Kono, Y. Shimanaka, H. Arai, H. Yamamoto, N. Mizushima, Autophagosome formation is initiated at phosphatidylinositol synthase-enriched ER subdomains, EMBO J, 36 (2017) 1719-1735.

[80] J. Kaur, M. Sawhney, S. Dattagupta, N.K. Shukla, A. Srivastava, R. Ralhan, Clinical significance of phosphatidyl inositol synthase overexpression in oral cancer, BMC Cancer, 10 (2010) 168.

[81] P.C. Thakur, J.M. Davison, C. Stuckenholz, L. Lu, N. Bahary, Dysregulated phosphatidylinositol signaling promotes endoplasmic-reticulum-stress-mediated intestinal mucosal injury and inflammation in zebrafish, Disease Models \&amp; Mechanisms, 7 (2014) 93-106.

[82] P.C. Thakur, C. Stuckenholz, M.R. Rivera, J.M. Davison, J.K. Yao, A. Amsterdam, K.C. Sadler, N. Bahary, Lack of de novo phosphatidylinositol synthesis leads to endoplasmic reticulum stress and hepatic steatosis in cdipt-deficient zebrafish, Hepatology, 54 (2011) 452-462.

[83] T.R. Murphy, T.S. Vihtelic, K.E. Ile, C.T. Watson, G.B. Willer, R.G. Gregg, V.A. Bankaitis, D.R. Hyde, Phosphatidylinositol synthase is required for lens structural integrity and photoreceptor cell survival in the zebrafish eye, Exp. Eye Res, 93 (2011) 460-474.

[84] S. Bahmanyar, Spatial regulation of phospholipid synthesis within the nuclear envelope domain of the endoplasmic reticulum, Nucleus, 6 (2015) 102-106.

[85] S. Bahmanyar, R. Biggs, A.L. Schuh, A. Desai, T. Müller-Reichert, A. Audhya, J.E. Dixon, K. Oegema, Spatial control of phospholipid flux restricts endoplasmic reticulum sheet formation to allow nuclear envelope breakdown, Genes \& Development, 28 (2014) 121-126.

[86] T.R. Pettitt, A. Martin, T. Horton, C. Liossis, J.M. Lord, M.J. Wakelam, Diacylglycerol and phosphatidate generated by phospholipases $C$ and $D$, respectively, have distinct fatty acid compositions and functions. Phospholipase D-derived diacylglycerol does not activate protein kinase C in porcine aortic endothelial cells, J Biol. Chem, 272 (1997) 17354-17359.

[87] R.H. Michell, Inositol phospholipids in cell surface receptor function, Biochim. Biophys. Acta, 415 (1975) 81-147.

[88] M.J. Broekman, J.W. Ward, A.J. Marcus, Fatty acid composition of phosphatidylinositol and phosphatidic acid in stimulated platelets. Persistence of arachidonyl-stearyl structure, J Biol. Chem, 256 (1981) 8271-8274.

[89] S.M. Prescott, P.W. Majerus, The fatty acid composition of phosphatidylinositol from thrombinstimulated human platelets, J. Biol. Chem, 256 (1981) 579-582.

[90] S. Rohit, P. Aniruddha, R. Padinjat, K. Sandeep, Evidence of sinks and sources in the phospholipase C-activated PIP2 cycle, FEBS Letters, 592 (2018) 962-972.

[91] Y.V. Shulga, D.S. Myers, P.T. Ivanova, S.B. Milne, H.A. Brown, M.K. Topham, R.M. Epand, Molecular species of phosphatidylinositol-cycle intermediates in the endoplasmic reticulum and plasma membrane, Biochemistry, 49 (2010) 312-317.

[92] C.-H. Liu, M.K. Bollepalli, S.V. Long, S. Asteriti, J. Tan, J.A. Brill, R.C. Hardie, Genetic dissection of the phophoinositide cycle in <em>Drosophila</em> photoreceptors, Journal of Cell Science, (2018). [93] R.C. Hardie, C.H. Liu, A.S. Randall, S. Sengupta, In vivo tracking of phosphoinositides in Drosophila photoreceptors, J Cell Sci, 128 (2015) 4328-4340. 
[94] T. Singal, N.S. Dhalla, P.S. Tappia, Regulation of c-Fos and c-Jun gene expression by phospholipase C activity in adult cardiomyocytes, Molecular and Cellular Biochemistry, 327 (2009) 229-239.

[95] A.M. Cardozo Gizzi, B.L. Caputto, Mechanistic insights into the nongenomic regulation of phospholipid synthesizing enzymes, IUBMB life, 65 (2013) 584-592.

[96] A.R. Alfonso Pecchio, A.M. Cardozo Gizzi, M.L. Renner, M. Molina-Calavita, B.L. Caputto, c-Fos activates and physically interacts with specific enzymes of the pathway of synthesis of polyphosphoinositides, Mol. Biol. Cell, 22 (2011) 4716-4725.

[97] L. Lai, M. Wang, O.J. Martin, T.C. Leone, R.B. Vega, X. Han, D.P. Kelly, A role for peroxisome proliferator-activated receptor gamma coactivator 1 (PGC-1) in the regulation of cardiac mitochondrial phospholipid biosynthesis, J Biol. Chem, 289 (2014) 2250-2259.

[98] J.M. Huss, R.P. Kopp, D.P. Kelly, Peroxisome proliferator-activated receptor coactivator-1alpha (PGC-1alpha) coactivates the cardiac-enriched nuclear receptors estrogen-related receptor-alpha and -gamma. Identification of novel leucine-rich interaction motif within PGC-1alpha, J Biol Chem, 277 (2002) 40265-40274.

[99] R.M. Gemmill, J. Roche, V.A. Potiron, P. Nasarre, M. Mitas, C.D. Coldren, B.A. Helfrich, E. Garrett-Mayer, P.A. Bunn, H.A. Drabkin, ZEB1-responsive genes in non-small cell lung cancer, Cancer Lett, 300 (2011) 66-78.

[100] M. Park, A. Sabetski, Y. Kwan Chan, S. Turdi, G. Sweeney, Palmitate Induces ER Stress and Autophagy in H9c2 Cells: Implications for Apoptosis and Adiponectin Resistance, Journal of Cellular Physiology, 230 (2015) 630-639.

[101] A. Imai, M.C. Gershengorn, Regulation by phosphatidylinositol of rat pituitary plasma membrane and endoplasmic reticulum phosphatidylinositol synthase activities. A mechanism for activation of phosphoinositide resynthesis during cell stimulation, J. Biol. Chem, 262 (1987) 64576459. 


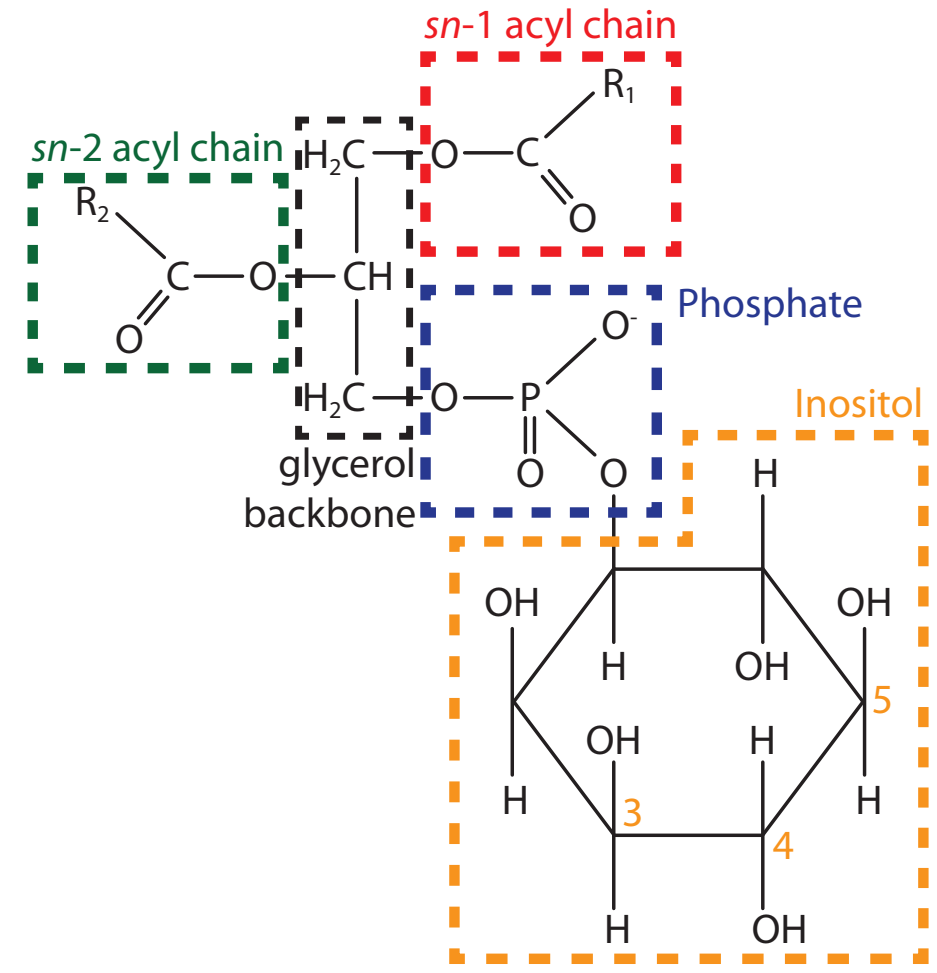

Phosphorylation by lipid kinases

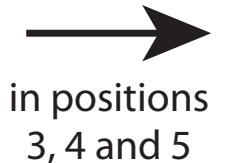

\section{$\mathrm{PI}(3) \mathrm{P}, \mathrm{PI}(4) \mathrm{P}, \mathrm{PI}(5) \mathrm{P}$}

$\mathrm{PI}(3,4) \mathrm{P}_{2}, \mathrm{PI}(3,5) \mathrm{P}_{2}, \mathrm{PI}(4,5) \mathrm{P}_{2}$ $\mathrm{PI}(3,4,5) \mathrm{P}_{3}$

Figure 1 


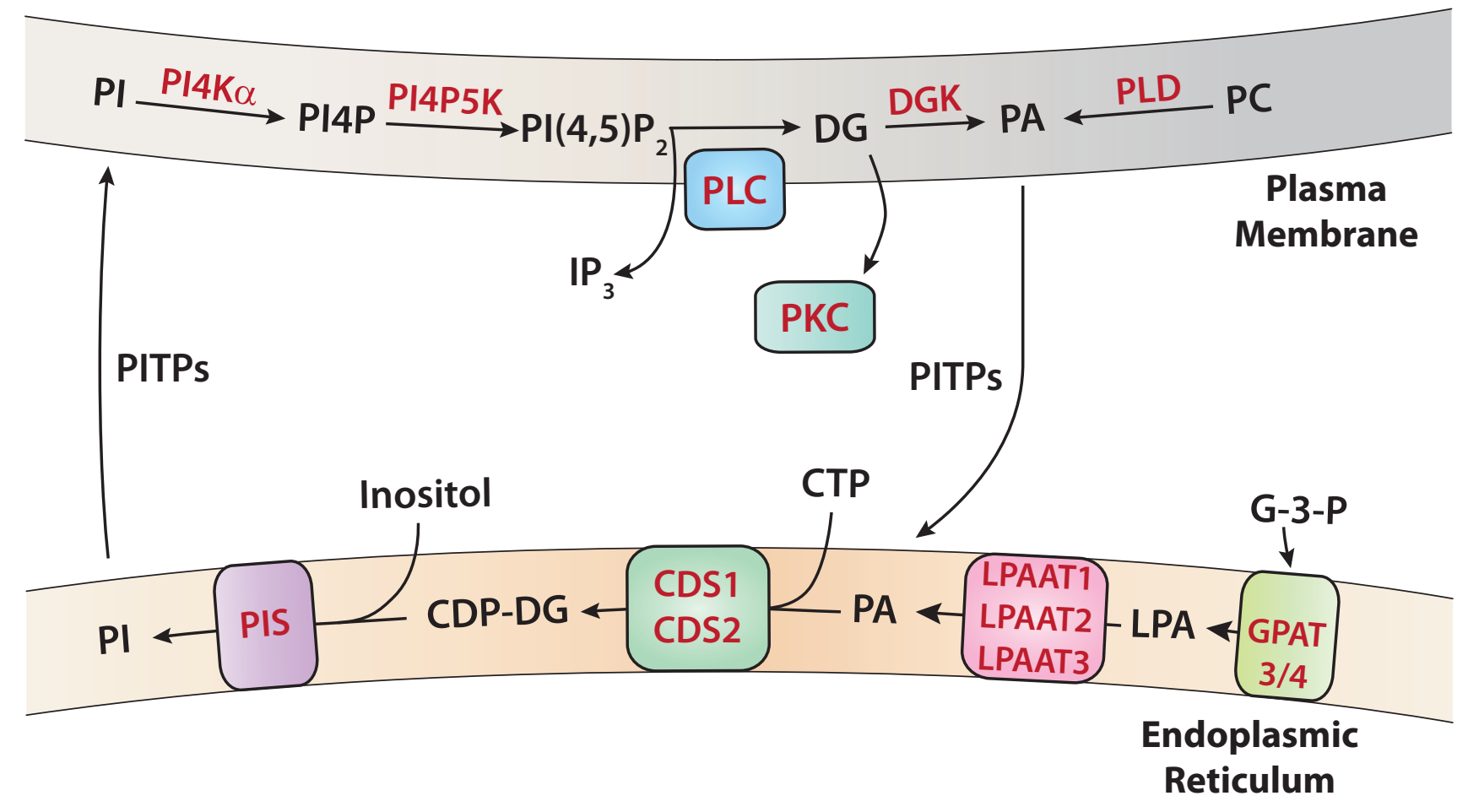

Figure 2 


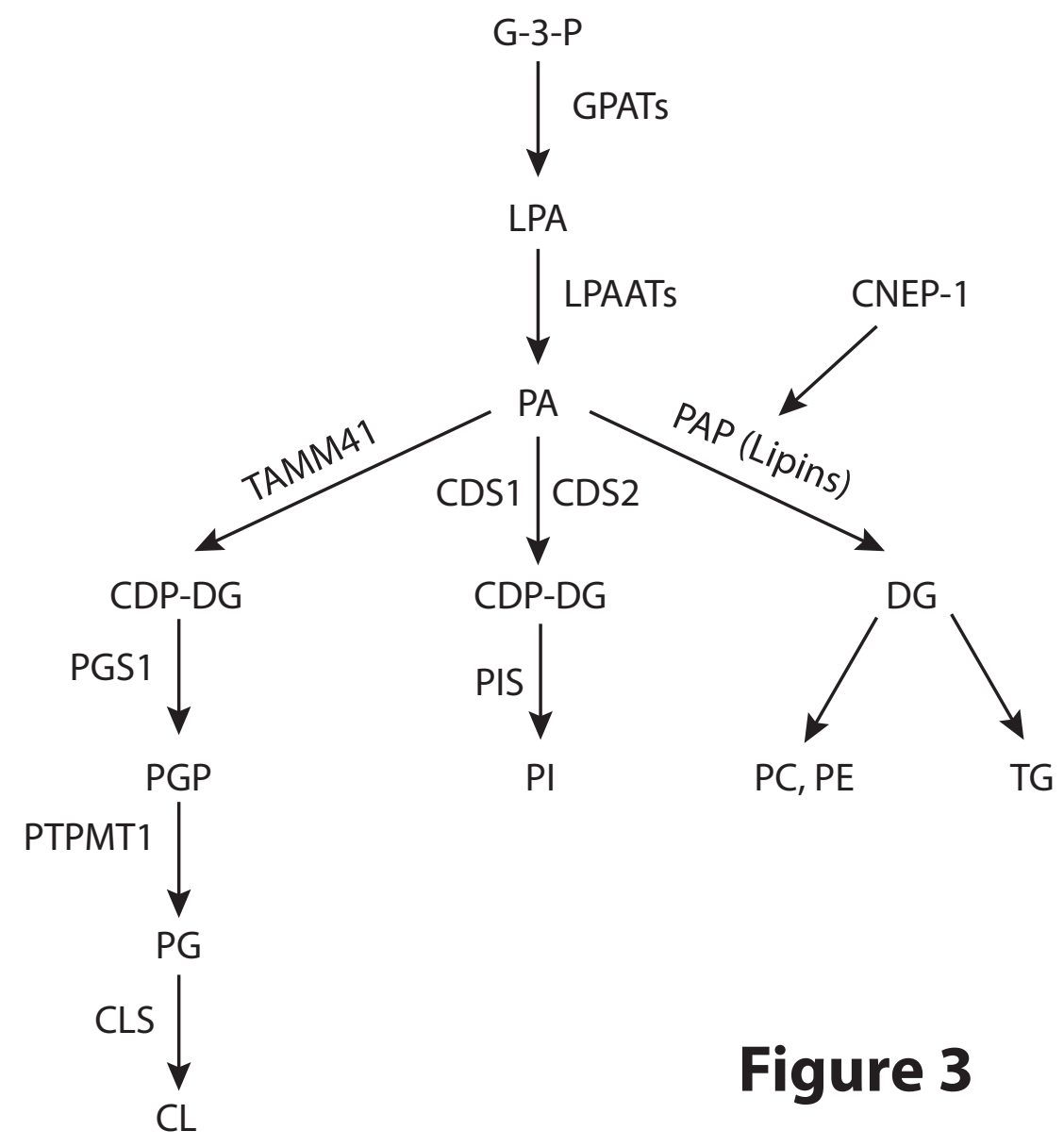


A

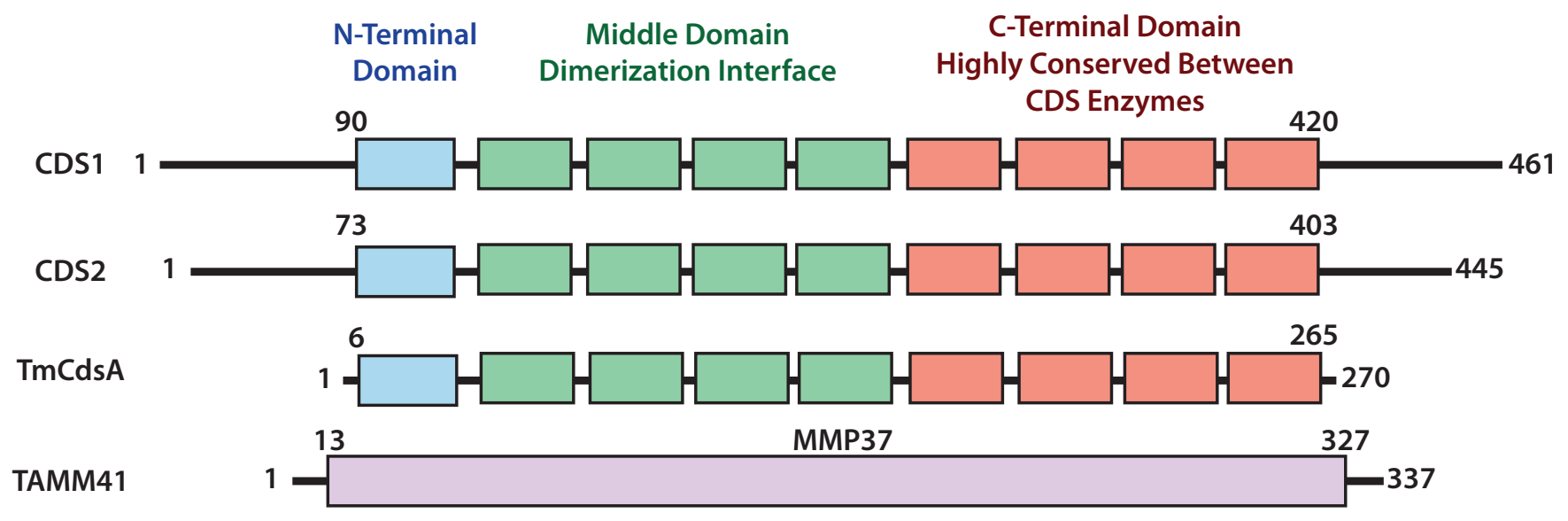

B

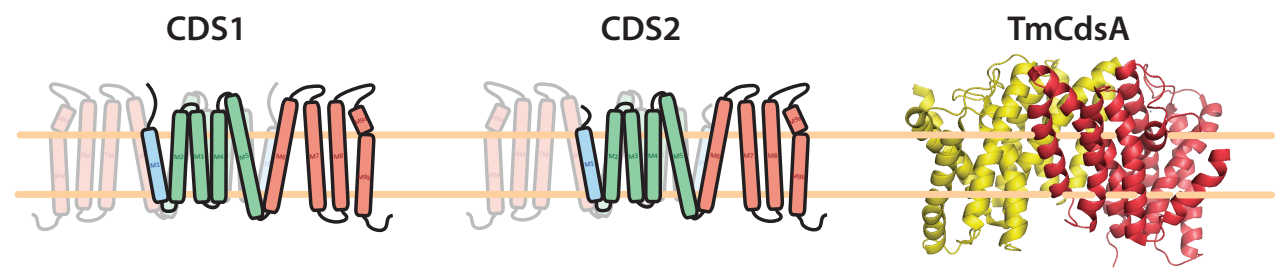

C

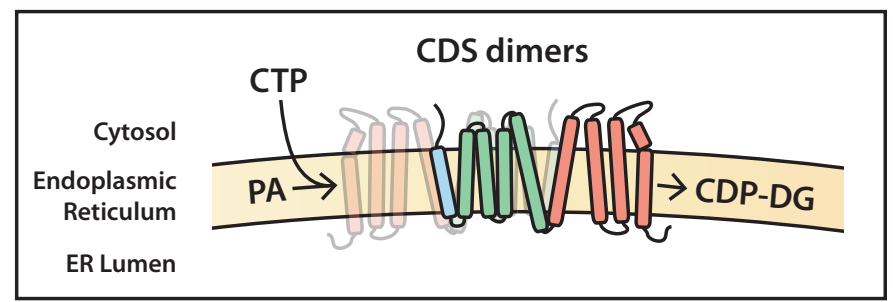

Endoplasmic Reticulum

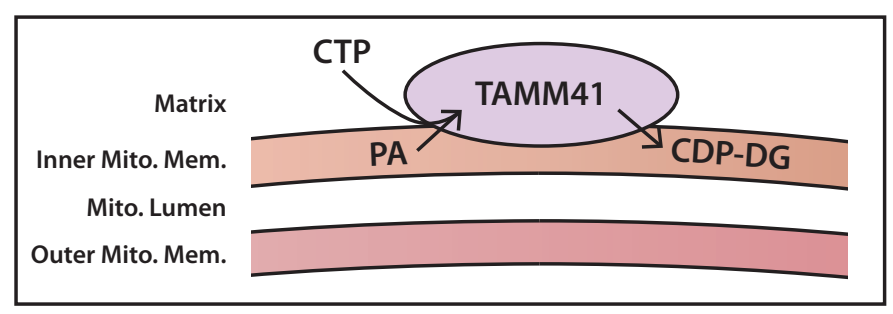

Mitochondria

Figure 4 


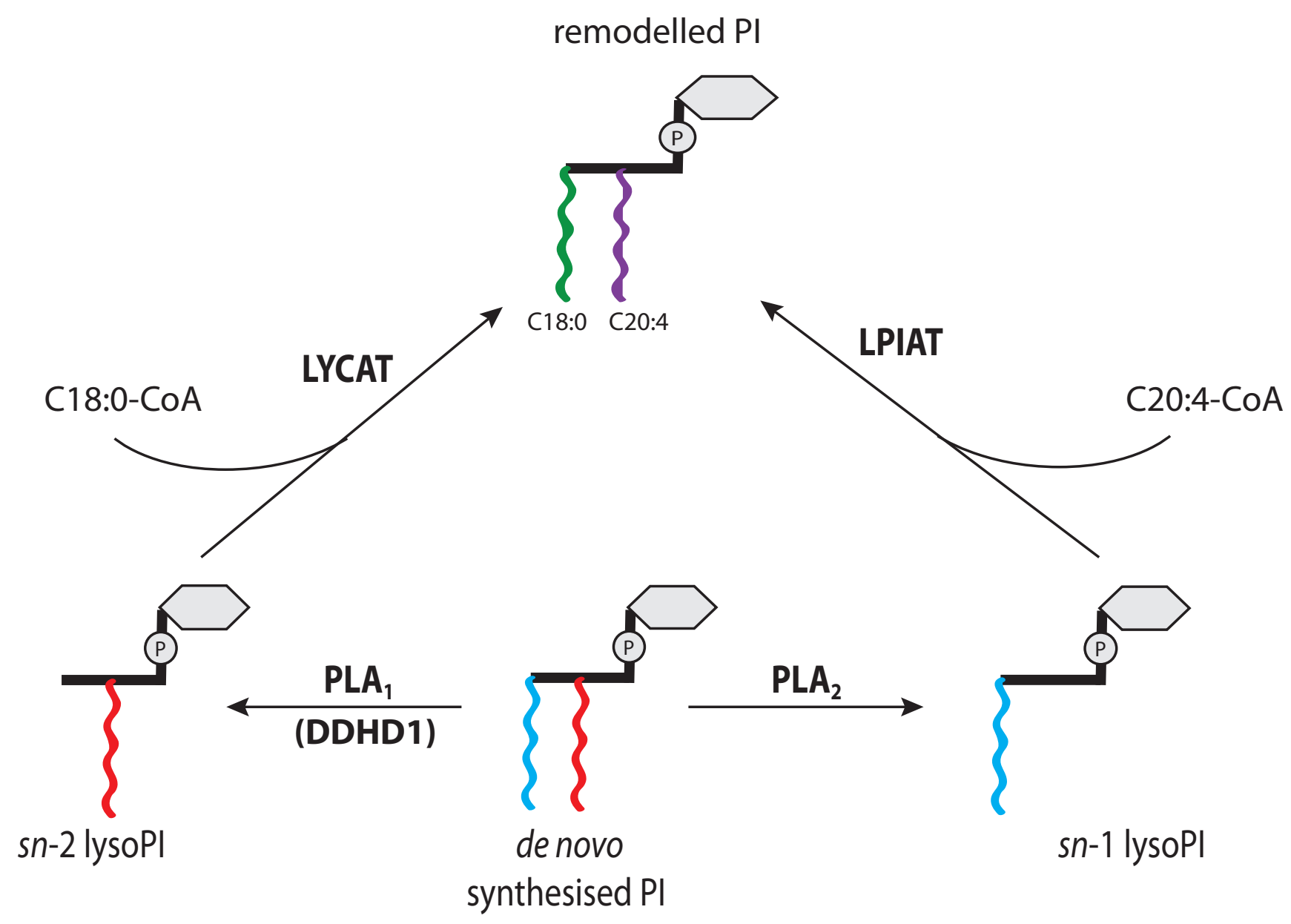

Figure 5 


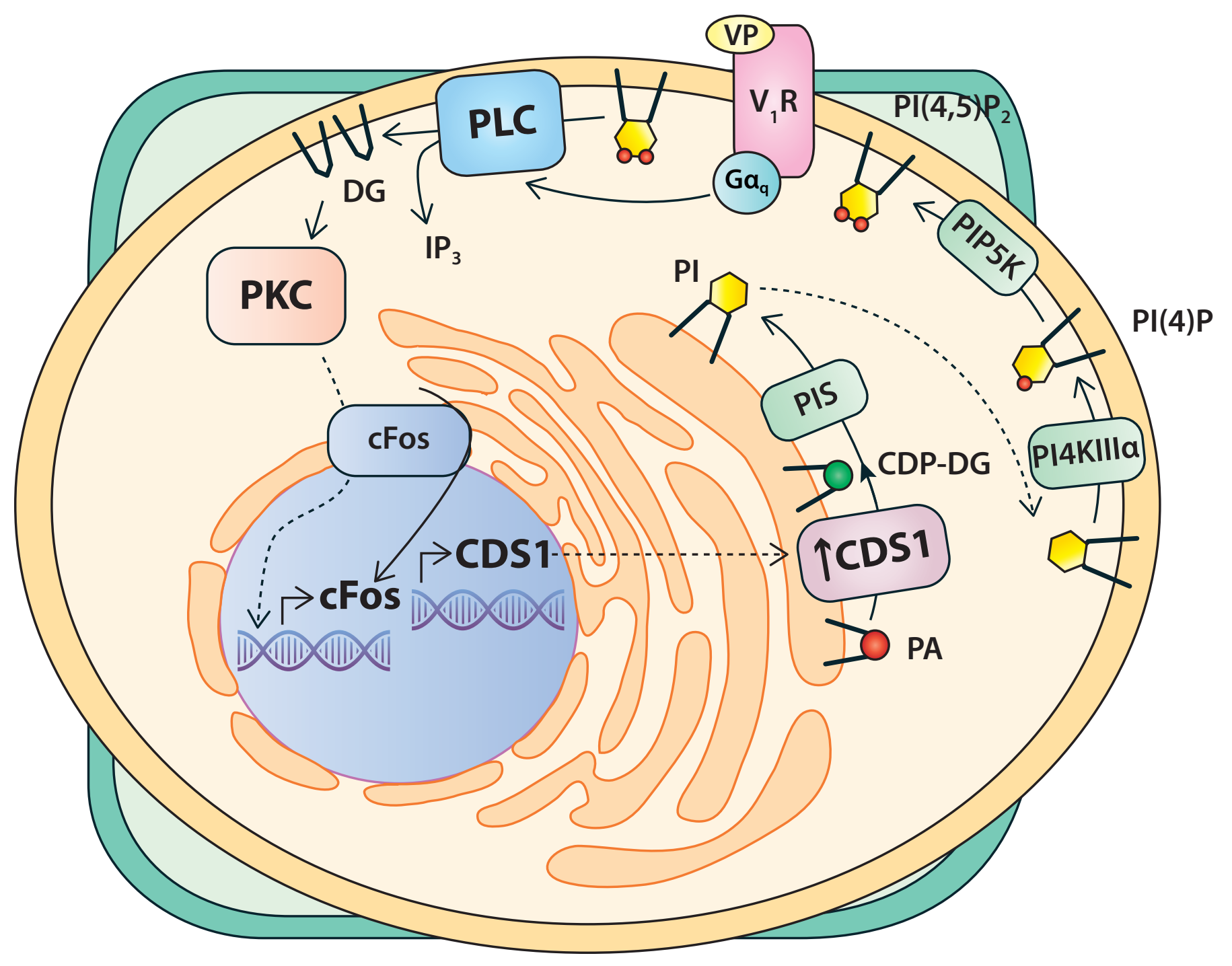

Figure 6 